ARTICLE

\title{
Steroidal and non-steroidal third-generation aromatase inhibitors induce pain-like symptoms via TRPA1
}

Camilla Fusi ${ }^{1, \star}$, Serena Materazzi ${ }^{1, \star}$, Silvia Benemei ${ }^{1, \star}$, Elisabetta Coppi ${ }^{1}$, Gabriela Trevisan ${ }^{2}$, Ilaria M. Marone ${ }^{1}$, Daiana Minocci ${ }^{1}$, Francesco De Logu', Tiziano Tuccinardi ${ }^{3}$, Maria Rosaria Di Tommaso ${ }^{4}$, Tommaso Susini ${ }^{4}$, Gloriano Moneti ${ }^{1,5}$, Giuseppe Pieraccini ${ }^{1,5}$, Pierangelo Geppetti ${ }^{1}$ \& Romina Nassini ${ }^{1}$

Use of aromatase inhibitors (Als), exemestane, letrozole and anastrozole, for breast cancer therapy is associated with severe pain symptoms, the underlying mechanism of which is unknown. The electrophilic nature of Als suggests that they may target the transient receptor potential ankyrin 1 (TRPA1) channel, a major pathway in pain transmission and neurogenic inflammation. Als evoke TRPA1-mediated calcium response and current in rodent nociceptors and human cells expressing the recombinant channel. In mice, Als produce acute nociception, which is exaggerated by pre-exposure to proalgesic stimuli, and, by releasing sensory neuropeptides, neurogenic inflammation in peripheral tissues. Als also evoke mechanical allodynia and decreased grip strength, which do not undergo desensitization on prolonged AI administration. These effects are markedly attenuated by TRPA1 pharmacological blockade or in TRPA1-deficient mice. TRPA1 is a major mediator of the proinflammatory/proalgesic actions of Als, thus suggesting TRPA1 antagonists for the treatment of pain symptoms associated with Al use.

\footnotetext{
${ }^{1}$ Department of Health Sciences, Section of Clinical Pharmacology and Oncology, University of Florence, Florence 50139, Italy. ${ }^{2}$ Laboratory of Biological and Molecular Biology, Graduate Program in Health Sciences, University of the Extreme South of Santa Catarina (UNESC), Santa Catarina 88806-000, Brazil. ${ }^{3}$ Department of Pharmacy, University of Pisa, Pisa 56126, Italy. ${ }^{4}$ Department of Health Sciences, Section of Pediatrics, Obstetrics and Gynecology and Nursing, Florence 50139, Italy. ${ }^{5}$ Mass Spectrometry Center, University of Florence, Florence 50139, Italy. ${ }^{\star}$ These authors contributed equally to this work. Correspondence and requests for materials should be addressed to P.G. (email: geppetti@unifi.it).
} 
T hird-generation aromatase inhibitors (AIs) are currently recommended for adjuvant endocrine treatment as primary, sequential or extended therapy with tamoxifen, for postmenopausal women diagnosed with oestrogen receptorpositive breast cancer ${ }^{1-3}$. AIs include the steroidal exemestane and non-steroidal azole derivatives, letrozole and anastrozole, which, via a covalent (exemestane) and non-covalent (azoles) binding, inactivate aromatase, the enzyme that catalyzes the conversion of androgens to oestrogens in peripheral tissue ${ }^{4}$. The use of AIs is, however, associated with a series of relevant side effects that are reported in 30-60\% of treated patients ${ }^{5,6}$. Among these, the AI-associated musculoskeletal symptoms (AIMSS) are characterized by morning stiffness and pain of the hands, knees, hips, lower back and shoulders ${ }^{7,8}$. In addition to musculoskeletal pain, pain symptoms associated with AIs have recently been more accurately described with the inclusion of neuropathic, diffused and mixed pain ${ }^{9}$. The whole spectrum of painful conditions has been reported to affect up to $40 \%$ of patients, and to lead $10-20 \%$ of patients to non-adherence or discontinuation of treatment ${ }^{7-14}$. Although it has been proposed that oestrogen deprivation and several other factors, including a higher level of anxiety, may contribute to the development of AIMSS and related pain symptoms, none of these hypotheses has been confirmed ${ }^{9,15}$. Thus, the exact mechanism of such conditions is still unclear and, consequently, patients are undertreated.

The transient receptor potential ankyrin 1 (TRPA1) channel, belonging to the larger family of the TRP channels ${ }^{16,17}$, is a polymodal sensor activated by chemical, mechanical and thermal stimuli ${ }^{18-23}$. TRPA1 is principally expressed by a subpopulation of primary sensory neurons ${ }^{24,25}$, which express additional TRPs, including the TRP vanilloid 1 (TRPV1) channel, which is selectively targeted by capsaicin, the hot ingredient of red peppers $^{16}$. TRPA1 and TRPV1 expressing pseudounipolar nociceptors produce and release from central and peripheral terminals the sensory neuropeptides, substance $\mathrm{P}$ (SP), neurokinin A (NKA) and calcitonin gene-related peptide (CGRP), which mediate neurogenic inflammation ${ }^{26}$. In particular, TRPA1 is the main target of many different irritant stimuli, such as allyl isothiocyanate (AITC, contained in mustard or wasabi) or cinnamaldehyde (contained in cinnamon), and of an unprecedented series of endogenous reactive molecules produced at sites of inflammation and tissue injury, including reactive oxygen (ROS), nitrative (RNS) or carbonyl (RCS) species ${ }^{19,27-30}$. TRPA1 is emerging as a major nociceptive and hyperalgesic mechanism in a variety of inflammatory pain models such as those induced by formalin, carrageenan and complete Freund adjuvant $\mathrm{t}^{31-34}$. Also, in models of neuropathic pain, such as those evoked by spinal nerve ligation ${ }^{35}$, streptozotocin ${ }^{36}$ and chemotherapeutic-induced peripheral neuropathy ${ }^{37-39}$, a key role of TRPA1 has been identified.

The chemical structure of exemestane includes a system of highly electrophilic conjugated Michael acceptor groups, which might react with the thiol groups of reactive cysteine residues ${ }^{40}$. Michael addition reaction with specific cysteine residues is a major mechanism that results in TRPA1 activation by a large variety of electrophilic compounds ${ }^{19,41,42}$. Aliphatic and aromatic nitriles can react with cysteine to form thiazoline derivatives and accordingly the tear gas 2-chlorobenzylidene malononitrile (CS) has been identified as a TRPAl agonist ${ }^{43}$. We noticed that both letrozole and anastrozole possess nitrile moieties. Thus, we hypothesized that exemestane, letrozole and anastrozole may produce neurogenic inflammation, nociception and hyperalgesia by targeting TRPA1. Our present findings show that AIs directly stimulate TRPA1, and via this pathway provoke neurogenic inflammatory oedema, acute nociception, mechanical allodynia and reduced grip strength, indicating a new mechanism through which AIs induce cytokine-independent inflammation and pain, and suggesting TRPA1 antagonists as possible innovative therapies for pain-like symptoms associated with the use of AIs.

\section{Results}

Aromatase inhibitors selectively activate TRPA1 channels. To explore whether AIs gate the human TRPA1 channel, we first used cells stably transfected with human TRPA1 cDNA (hTRPA1-HEK293). In hTRPA1-HEK293 cells, which respond to the selective TRPA1 agonist AITC $(30 \mu \mathrm{M})$, but not in untransfected HEK293 cells, the three AIs, exemestane, letrozole and anastrozole, evoked concentration-dependent calcium responses that were inhibited by the selective TRPA1 antagonist, HC$030031(30 \mu \mathrm{M})^{44}$ (Fig. 1a-c). EC 50 of AIs ranged between 58 and $134 \mu \mathrm{M}$ (Fig. 1b). The calcium response was abated in a calciumfree medium, thus supporting the hypothesis that the increase in intracellular calcium originates from extracellular sources (Supplementary Fig. 1a). In HEK293 cells stably transfected with human TRPV1 cDNA (hTRPV1-HEK293) all AIs (100 $\mu \mathrm{M})$ were ineffective (Supplementary Fig. 1b). Key amino-acid residues are required for channel activation by electrophilic TRPA1 agonists ${ }^{19,41,42}$. Notably, HEK293 cells expressing a mutated TRPA1 channel (3C/K-Q), which presents substitutions of three cysteine with serine (C619S, C639S, C663S) and one lysine with glutamine (K708Q) residues, were insensitive to both AITC ${ }^{19,41}$ and all three AIs, while maintaining sensitivity to the non-electrophilic agonists, menthol ${ }^{29}$ or icilin ${ }^{42}$ (Fig. 1d and Supplementary Fig. 1c). This finding supports the hypothesis that the ability of AIs to target TRPA1 derives from their electrophilic nature. Electrophysiology experiments recapitulated findings obtained by means of the calcium assay. Exemestane, letrozole and anastrozole selectively activated a concentration-dependent inward current in hTRPA1-HEK293 cells, a response that was abated by HC-030031 (Supplementary Fig. 1d). AIs did not evoke any current in untransfected HEK293 cells (Supplementary Fig. 1d).

Next, to verify whether exemestane, letrozole and anastrozole stimulate nociceptive sensory neurons via TRPA1 activation, we used primary culture of both rat and mouse dorsal root ganglion (DRG) neurons. Similar to AITC ${ }^{19}$, all AIs produced a concentration-dependent calcium response (Fig. 2a,b) in a proportion (about 30\%) of cells that responded to the selective TRPV1 agonist, capsaicin $(0.1 \mu \mathrm{M})$. All cells responding to AIs, but none of the non-responding cells, invariably responded to a subsequent high concentration of AITC $(30 \mu \mathrm{M})$ (Fig. 2a), further documenting TRPA1 as the target of AIs. In rat DRG neurons, $\mathrm{EC}_{50}$ ranged between 78 and $135 \mu \mathrm{M}$ (Fig. 2b). Calcium responses evoked by the three AIs were abated by HC-030031 $(30 \mu \mathrm{M})$, but were unaffected by the selective TRPV1 antagonist, capsazepine $(10 \mu \mathrm{M})$ (Fig. 2c). Notably, AITC and all AIs produced a calcium response in capsaicin-sensitive DRG neurons isolated from wildtype $\left(\right.$ Trpa $\left.1^{+/+}\right)$mice, an effect that was absent in neurons obtained from TRPA1-deficient $\left(\operatorname{Trpa1} 1^{-/-}\right)$mice (Typical traces Fig. 2d and pooled data Fig. 2e).

AIs activate nociceptive and hyperalgesic TRPA1-dependent pathways. It has been well documented that local exposure to TRPA1 agonists in experimental animals is associated with an immediate nociceptive response, lasting for a few minutes, and a delayed more prolonged mechanical allodynia ${ }^{18,19}$. To investigate whether AIs activate such a nociceptive and hyperalgesic TRPA1dependent pathway, we used one steroidal (exemestane) and one non-steroidal (letrozole) AI. Given the chemical similarity and the hypothesized analogous mechanism of the two non-steroidal AIs, to minimize the number of animals used, anastrozole was not 

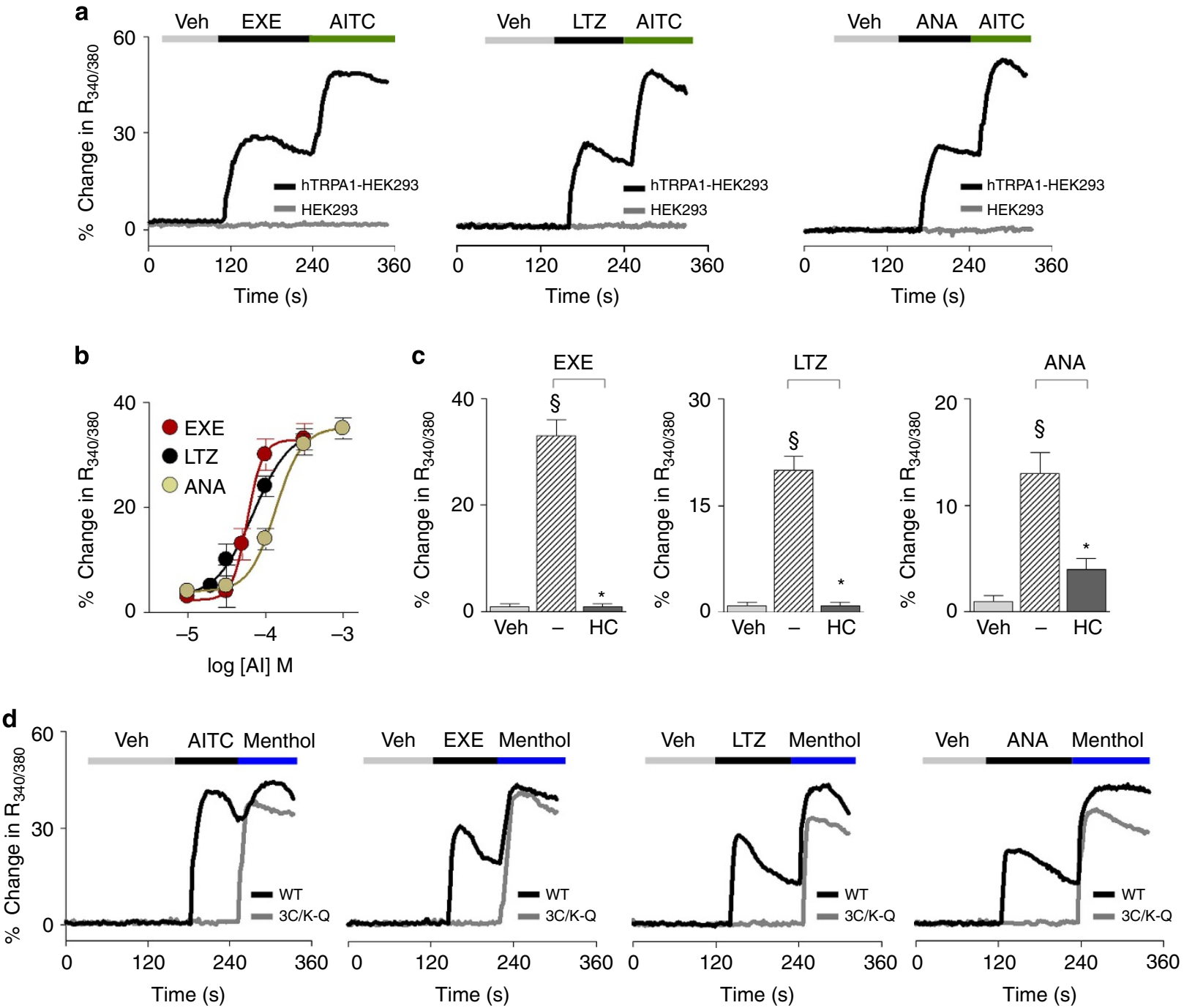

Figure 1 | Exemestane (EXE), letrozole (LTZ) and anastrozole (ANA) selectively activate the human TRPA1 channel. (a) Representative traces of intracellular calcium response evoked by the aromatase inhibitors (Als), EXE $(100 \mu \mathrm{M})$, LTZ $(100 \mu \mathrm{M})$ and ANA $(100 \mu \mathrm{M})$, in HEK293 cells transfected with the cDNA for human TRPA1 (hTRPA1-HEK293), which respond to the selective TRPA1 agonist, allyl isothiocyanate (AITC; $30 \mu \mathrm{M})$. AITC (30 $\mu$ M), EXE, LTZ and ANA (all $100 \mu \mathrm{M}$ ) fail to produce any calcium response in untransfected-HEK293 cells (HEK293). (b) Concentration-response curves to EXE, LTZ and ANA, yielded $\mathrm{EC}_{50}$ (95\% confidence interval) of 58 (46-72) $\mu \mathrm{M}, 69$ (43-109) $\mu \mathrm{M}$, and 134 (96-186) $\mu \mathrm{M}$, respectively. (c) Al-evoked calcium response in hTRPA1-HEK293 is abolished by the selective TRPA1 antagonist, HC-030031 (HC; $30 \mu \mathrm{M})$. (d) Representative traces of cells transfected with the cDNA codifying for the mutant hTRPA1 channel $(3 \mathrm{C} / \mathrm{K}-\mathrm{Q})$, which are insensitive to AITC $(30 \mu \mathrm{M})$ or Als $(100 \mu \mathrm{M})$, but respond to the non-electrophilic agonist, menthol $(100 \mu \mathrm{M})$, whereas HEK293 cells transfected with the cDNA codifying for wild-type hTRPA1 (WT) respond to all the drugs. Veh is the vehicle of Als; dash $(-)$ indicates the vehicle of HC. Each point or column represents the mean \pm s.e.m. of at least 25 cells from 3-6 independent experiments. ${ }^{\$} P<0.05$ versus Veh, ${ }^{\star} P<0.05$ versus EXE, LTZ or ANA group; ANOVA and Bonferroni post hoc test.

investigated in the following in vivo experiments. Intraplantar (i.pl.) injection $(20 \mu \mathrm{l}$ per paw) of exemestane $(1,5$ and $10 \mathrm{nmol})$ (Supplementary Fig. 2a) or letrozole $(10,20 \mathrm{nmol})$ (Supplementary Fig. 2e) evoked an acute (0-5 min) nociceptive response and a delayed (15-120 min for exemestane and 15$240 \mathrm{~min}$ for letrozole) mechanical allodynia in C57BL/6 mice (Supplementary Fig. 2c,g). Both the nociceptive response and mechanical allodynia evoked by AIs were confined to the treated paw (Supplementary Fig. 2c,g) and were almost completely prevented by intraperitoneal (i.p.) pretreatment with HC-030031 $\left(100 \mathrm{mg} \mathrm{kg}^{-1}\right)$, but not with capsazepine $\left(4 \mathrm{mg} \mathrm{kg}^{-1}\right)$ (Supplementary Fig. 2b,d,f,h). Furthermore, similar to results obtained in C57BL/6 mice, local injection (i.pl.) of exemestane or letrozole in Trpa1 ${ }^{+/+}$mice evoked an early nociceptive response and a delayed mechanical allodynia (Supplementary Fig. 2i,j). Trpa1 ${ }^{-/-}$mice did not develop such responses (Supplementary
Fig. 2i,j). Thus, by using both pharmacological and genetic tools, we demonstrated that local administration of both steroidal and non-steroidal AIs produces a typical TRPA1-dependent behaviour, characterized by acute nociception and delayed mechanical allodynia.

AIs produce neurogenic oedema by releasing sensory neuropeptides. TRPA1 is expressed by peptidergic nociceptors, and its stimulation is associated with proinflammatory neuropeptide release and the ensuing neurogenic inflammatory responses ${ }^{19,45}$. First, we explored whether AIs are able to directly promote the release of CGRP (one of the proinflammatory neuropeptides, which are usually co-released on stimulation of peptidergic nociceptors ${ }^{26,46}$ via a TRPA1-dependent pathway. AIs increased CGRP outflow from slices of rat dorsal spinal cord (an anatomical 

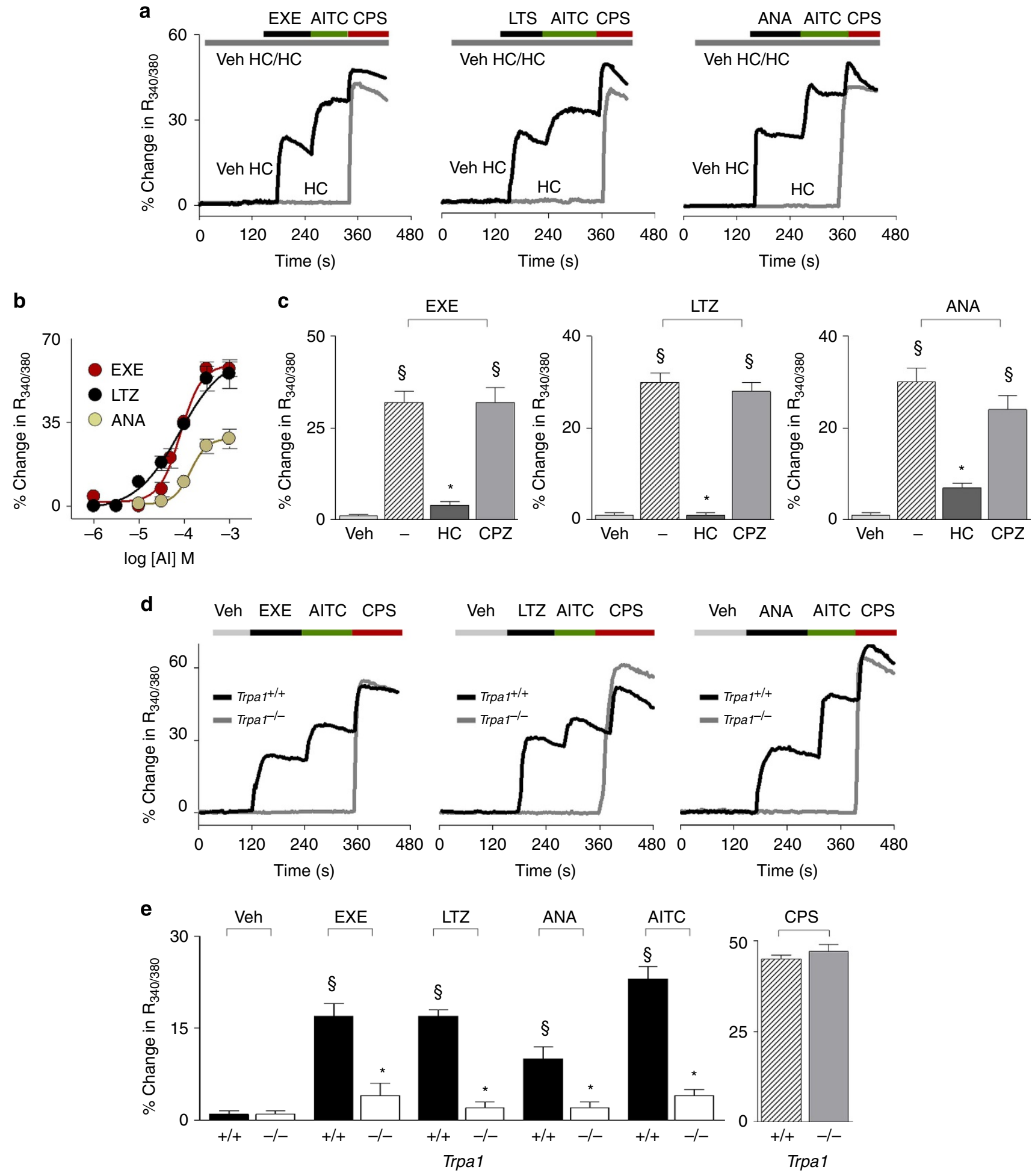

Figure 2 | Exemestane (EXE), letrozole (LTZ) and anastrozole (ANA) selectively activate the native TRPA1 channel expressed in rodent dorsal root ganglion (DRG) neurons. (a) Representative traces of calcium response evoked by EXE $(100 \mu \mathrm{M})$, LTZ $(100 \mu \mathrm{M})$, ANA (300 $\mu \mathrm{M})$ in cultured rat DRG neurons, which also respond to allyl isothiocyanate (AITC; $30 \mu \mathrm{M}$ ) and capsaicin (CPS; $0.1 \mu \mathrm{M}$ ). Calcium responses evoked by Als and AITC are abolished by the selective TRPA1 antagonist, HC-030031 (HC; $30 \mu \mathrm{M}$ ), which does not affect response to CPS. (b) Concentration-response curves of EXE, LTZ and ANA, yielded $\mathrm{EC}_{50}$ (95\% confidence interval) of 82 (61-108) $\mu \mathrm{M}, 78$ (39-152) $\mu \mathrm{M}$, and 135 (78-231) $\mu \mathrm{M}$, respectively. (c) Calcium responses induced by Als are inhibited by $\mathrm{HC}$ and unaffected by the TRPV1 antagonist, capsazepine $(\mathrm{CPZ} ; 10 \mu \mathrm{M}) .{ }^{\S} P<0.05$ versus Veh, ${ }^{\star} P<0.05$ versus EXE, LTZ or ANA; ANOVA and Bonferroni post hoc test. (d) Representative traces and (e) pooled data of the calcium response evoked by EXE, LTZ, ANA (all 100 $\mu M$ ) or AITC $(30 \mu \mathrm{M})$, in neurons isolated from Trpa ${ }^{+/+}$mice. Neurons isolated from Trpa ${ }^{-/-}$mice do not respond to AITC, EXE, LTZ and ANA, whereas they do respond normally to CPS $(0.1 \mu \mathrm{M})$. In DRG neurons isolated from both Trpa1 ${ }^{+/+}$and Trpa1 ${ }^{-/-}$mice, calcium response is evaluated only in capsaicin responding neurons. ${ }^{\$} P<0.05$ versus Veh, ${ }^{\star} P<0.05$ versus EXE, LTZ, ANA or AITC-Trpa1 ${ }^{+/+}$, ANOVA and Bonferroni post hoc test. Veh is the vehicle of Als; dash (-) indicates the combination of the vehicles of $\mathrm{HC}$ and CPZ. Each point or column represents the mean \pm s.e.m. of at least 25 neurons obtained from 3 to 7 independent experiments. 
area enriched with central terminals of nociceptors). This effect was substantially attenuated in rat slices pretreated with a desensitizing concentration of capsaicin $(10 \mu \mathrm{M}, 20 \mathrm{~min})$ or in the presence of HC-030031 (Fig. 3a). The increase in CGRP outflow observed in slices obtained from Trpa1 $1^{+/+}$mice was markedly reduced in slices obtained from Trpa1 ${ }^{-/-}$mice (Fig. 3b).

These neurochemical data were corroborated by functional experiments. Injection (i.pl.) of the TRPA1 agonist, AITC $(10 \mathrm{nmol}$ per paw), induced paw oedema that peaked at $60 \mathrm{~min}$ after injection. The response was abated by treatment with HC$030031\left(100 \mathrm{mg} \mathrm{kg}^{-1}\right.$, i.p.) or a combination of the SP neurokinin-1 (NK-1) receptor antagonist, L-733,060, and the CGRP receptor antagonist, CGRP8-37 (both, $2 \mu \mathrm{mol} \mathrm{kg}^{-1}$, intravenous, i.v.) (Fig. 3c). Similarly, we found that i.pl. administration of exemestane ( $10 \mathrm{nmol}$ per paw) and letrozole ( $20 \mathrm{nmol}$ per paw) caused paw oedema that peaked at $60 \mathrm{~min}$ and faded $120 \mathrm{~min}$ after injection (Fig. 3c, insets). Treatment with HC-030031 (100 mg kg-1, i.p.) or a combination of L-733,060 and CGRP8-37 (both, $2 \mu \mathrm{mol} \mathrm{kg}{ }^{-1}$, i.v.), markedly reduced the AI-evoked oedema (Fig. 3c). No oedema was found in the paw contralateral to that injected with AIs (Supplementary Fig. 2k). Importantly, the oedema produced in Trpa $1^{+/+}$mice by exemestane and letrozole was markedly attenuated in Trpa1 ${ }^{-1}$ - mice (Fig. 3d). Next, to directly evaluate the ability of AIs to release CGRP from peripheral terminals of peptidergic nociceptors, AIs were administered to the rat knee joint. Intra-articular (i.a., $50 \mu \mathrm{l})$ injection of exemestane $(5 \mathrm{nmol})$ or letrozole $(10 \mathrm{nmol})$ increased CGRP levels in the synovial fluid, an effect that was markedly attenuated by pretreatment with HC-030031 (100 $\mathrm{mg} \mathrm{kg}^{-1}$, i.p.) (Fig. 3e). Neurochemical and functional data indicate that AIs by TRPA1 activation release sensory neuropeptides from sensory nerve endings, and by this mechanism promote neurogenic inflammatory responses in the innervated peripheral tissue.

Systemic AIs induce prolonged pain-like effects by targeting TRPA1. AIs are given to patients by a systemic route of administration. Therefore, we explored in mice whether intraperitoneal (i.p.) or intragastric (i.g.) administration of exemestane and letrozole could produce pain-like effects via TRPA1 activation. For i.p. administration experiments, doses, corresponding to those used in humans, were selected according to the mouse to human conversion factor indicated by the National Institute of Health ${ }^{47}$. Exemestane $\left(5 \mathrm{mg} \mathrm{kg}^{-1}\right.$, i.p. $)$ or letrozole $\left(0.5 \mathrm{mg} \mathrm{kg}^{-1}\right.$, i.p) injection did not produce any visible nociceptive behaviour (Supplementary Figs 3a,4a, insets) in mice. However, $3 \mathrm{~h}$ after exemestane or letrozole administration, mice developed a prolonged $(3 \mathrm{~h})$ mechanical allodynia (Supplementary Figs 3a,4a) and a reduction in forelimb grip strength (Supplementary Figs $3 c, 4 c$ ), a test used in its clinical version for the study of musculoskeletal pain in patients ${ }^{48}$. When mechanical allodynia by exemestane or letrozole was at its maximum, systemic HC030031 administration $\left(100 \mathrm{mg} \mathrm{kg}^{-1}\right.$, i.p.) transiently reverted both responses (Supplementary Figs 3b,d and 4b,d). Furthermore, mechanical allodynia and the reduction in forelimb grip strength produced by exemestane and letrozole in Trpa1 ${ }^{+/}+$mice were markedly reduced in Trpa1 ${ }^{-/-}$mice (Supplementary Figs 3e,f and $4 \mathrm{e}, \mathrm{f})$. In experiments where AIs were given by intragastric (i.g.) gavage, doses were adjusted considering the oral bioavailability in humans, which is $99 \%$ for letrozole ${ }^{49}$, and $40 \%$ (with food) for exemestane ${ }^{50}$. First, we found that after i.g. administration of exemestane $\left(10 \mathrm{mg} \mathrm{kg}^{-1}\right)$ or letrozole $\left(0.5 \mathrm{mg} \mathrm{kg}^{-1}\right)$ their peak plasma levels $\left(13.2 \pm 1.7 \mathrm{ng} \mathrm{ml}^{-1}\right.$, $n=5$; and $60.5 \pm 12.1 \mathrm{ng} \mathrm{ml}^{-1}, n=5$, respectively, Supplementary Fig. 5) approximated the maximum plasma concentrations found in humans $s^{49,51}$. Second, results similar to those obtained after i.p. administration were reported when AIs were given by i.g. gavage. First, exemestane $\left(10 \mathrm{mg} \mathrm{kg}^{-1}\right.$, i.g. $)$ or letrozole $\left(0.5 \mathrm{mg} \mathrm{kg}^{-1}\right.$, i.g. $)$ ingestion was not associated with any spontaneous nocifensor behaviour (Figs $4 \mathrm{a}, 5 \mathrm{a}$, insets). Second, exemestane or letrozole produced, with a similar time-course, mechanical allodynia and a marked reduction in forelimb grip strength (Figs 4a,c and 5a,c). Pretreatment with HC-030031 or deletion of TRPA1 (Trpa1 ${ }^{-/-}$mice) significantly attenuated both responses (Figs $4 b, d, e, f$ and $5 b, d, e, f$.

Furthermore, since in clinical practice patients are treated with AIs on a daily basis over very long periods of time (up to 5 years), we asked whether exemestane or letrozole maintains the ability to evoke a TRPA1-dependent mechanical hypersensitivity and decreased grip strength on repeated administration. In Trpa $1^{+/+}$mice, treatment with systemic exemestane $\left(5 \mathrm{mg} \mathrm{kg}^{-1}\right.$, i.p.) or letrozole $\left(0.5 \mathrm{mg} \mathrm{kg}^{-1}\right.$ i.p) (both once a day for 15 consecutive days) produced at day $1,5,10$ and 15 a transient (from 1 to $6 \mathrm{~h}$ ) and reproducible mechanical allodynia (Supplementary Figs 3e, 4e). Importantly, in Trpa1 ${ }^{-/-}$the proalgesic action of AIs was markedly attenuated (Supplementary Figs $3 \mathrm{e}, 4 \mathrm{e})$. In addition, the decrease in the grip strength was maintained, without undergoing desensitization, over the entire time period of daily i.p. administration of exemestane or letrozole (Supplementary Figs 3f,4f). Both these effects of AIs were significantly reduced in Trpa1 ${ }^{-/-}$mice (Supplementary Figs 3f, 4f). Similar results were obtained after i.g. administration of exemestane or letrozole (once a day for 15 consecutive days at the dose of $10 \mathrm{mg} \mathrm{kg}^{-1}$ i.g. or $0.5 \mathrm{mg} \mathrm{kg}^{-1}$ i.g., respectively). Both mechanical allodynia and decreased grip strength were observed, without signs of desensitization, over the 15 days of observation in $\operatorname{Trpa1}^{+/+}$mice, but were markedly reduced in $\operatorname{Trpa1} 1^{-1-}$ mice (Figs $4 \mathrm{e}, \mathrm{f}$ and $5 \mathrm{e}, \mathrm{f}$ ). Altogether, the present data demonstrate that both steroidal and non-steroidal third-generation AIs induce a series of pain-like effects predominantly via a TRPA1-dependent mechanism, effects that over time do not undergo desensitization, thus mimicking the chronic clinical condition.

AI-evoked TRPA1 activation is enhanced by proinflammatory stimuli. Although it affects a large proportion of subjects, not all patients treated with AIs develop AIMSS. One possible explanation for the peculiar susceptibility to AIMSS of some patients is that, if TRPA1 activation is a necessary prerequisite, per se it is not sufficient, and additional proalgesic factors must contribute to the development of pain symptoms. It has been reported that stimulation of proalgesic pathways exaggerates TRPA1-dependent responses in vitro and in vivo ${ }^{52,53}$. One example of such potentiating action has been reported for the proteinase-activated receptor-2 (PAR2), whose subthreshold activation results in an exaggerated response to the TRPA1 agonist, AITC ${ }^{52}$. PAR2 undergoes activation on a unique proteolytic mechanism by cleavage of its tethered ligand domain by trypsin and other proteases, thus mediating inflammation and hyperalgesia ${ }^{54}$. On this basis, and following a previously reported protocol ${ }^{52}$, we explored, by in vivo functional experiments in C57BL/6 mice, whether PAR2 activation exaggerates TRPA1-dependent hypersensitivity induced by AIs. Before $(10 \mathrm{~min})$ injection (i.pl.) of the PAR2-activating peptide (AP) (PAR2-AP, $1 \mu \mathrm{g}$ per paw), but not the reverse peptide (RP) (PAR2-RP, $1 \mu$ g per paw, inactive on PAR2), markedly enhanced the duration of licks and flinches of the hind paw produced by local injection (i.pl.) of exemestane ( 1 nmol per paw) and letrozole (10 nmol per paw) (Fig. 6a). The injected dose of PAR2-AP, as well as PAR2-RP, did not cause per se any visible acute nocifensor response (Fig. 6a). The exaggerated responses to the combination of PAR2-AP and 
a
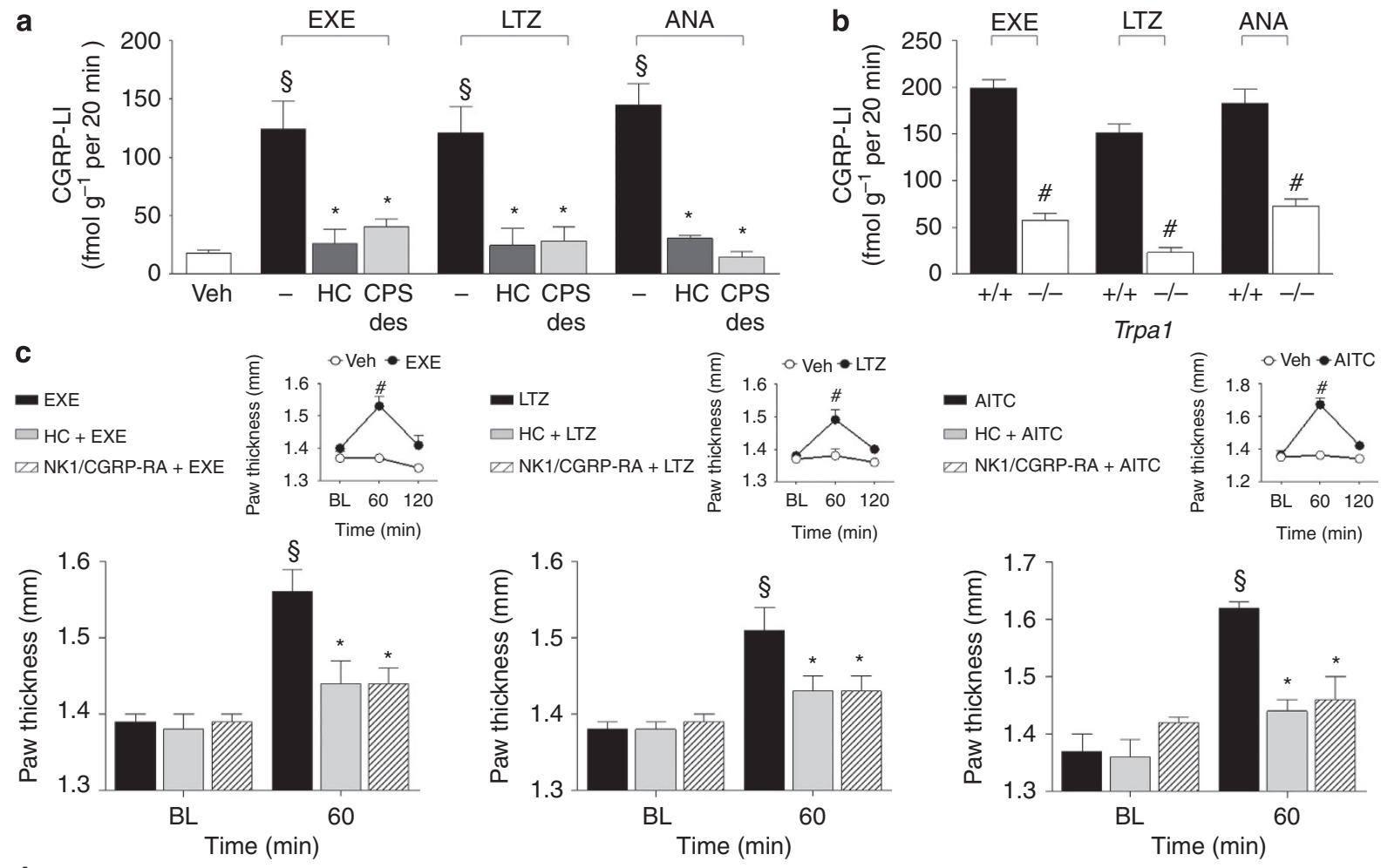

d $\square$ Veh-Trpa1 ${ }^{+/+} \quad \square$ Veh-Trpa1 ${ }^{-/-}$

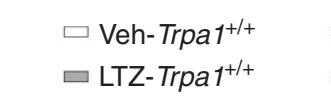
$\square$ Veh-Trpa1 ${ }^{-/-}$
$\square$ LTZ-Trpa1 $^{-/-}$

$\square$ Veh-Trpa1 ${ }^{+/+}$

$\square$ Veh-Trpa1 ${ }^{-1-}$ $\square$ EXE-Trpa1 ${ }^{+/+}$

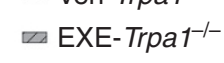

$\square$ AITC-Trpa1 ${ }^{+/+}$

$\square$ AITC-Trpa1 ${ }^{-1-}$
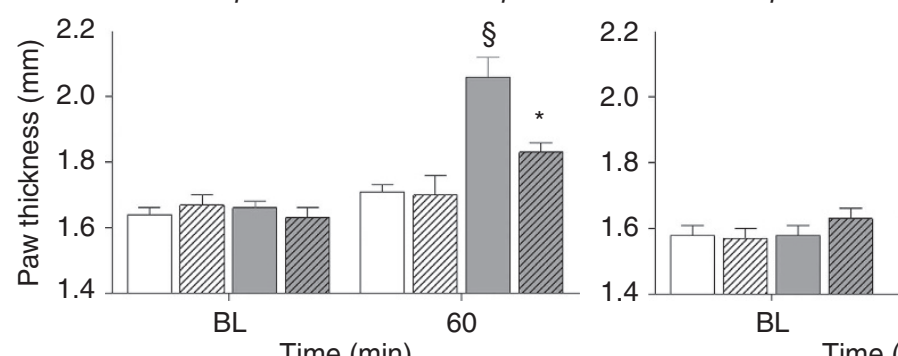

BL

Time (min)

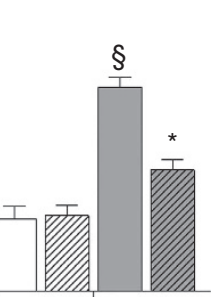

60

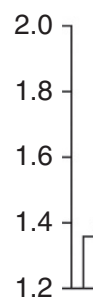

1.2 IIA

BL Time (min) 60
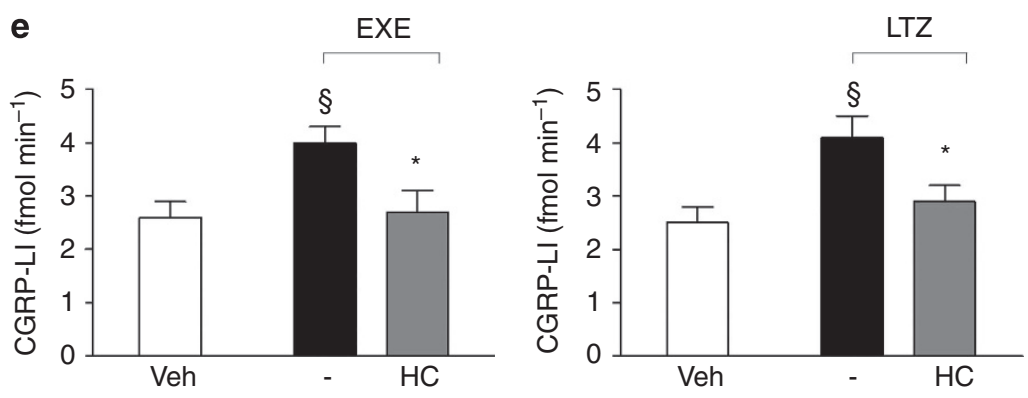

Figure 3 | Aromatase inhibitors release calcitonin gene-related peptide (CGRP) and produce neurogenic edema. (a) Exemestane (EXE), letrozole (LTZ) and anastrozole (ANA) (all $100 \mu \mathrm{M}$ ) increase the CGRP-like immunoreactivity (CGRP-LI) outflow from slices of rat dorsal spinal cord. This effect is prevented by HC-030031 (HC; $30 \mu \mathrm{M})$ or after exposure to capsaicin $(10 \mu \mathrm{M}, 20 \mathrm{~min}$; CPS-des). (b) EXE, LTZ and ANA (all $100 \mu \mathrm{M})$ increase the CGRP-LI outflow from spinal cord slices obtained from Trpa ${ }^{+/+}$, but not from Trpa1 ${ }^{-/-}$mice. Results are mean \pm s.e.m. of at least four independent experiments. Veh is the vehicle of EXE, LTZ and ANA, dash (-) indicates the vehicle of HC and CPS. ${ }^{\$} P<0.05$ versus Veh, ${ }^{\star} P<0.05$ versus EXE, LTZ or ANA; ANOVA followed by Bonferroni post hoc test. ${ }^{*} P<0.05$ versus EXE-, LTZ-, ANA-Trpa1 $+/+$, Student's t-test. (c) In C57BL/6 mice intraplantar (i.pl.) injection (20 $\mu$ l) of EXE $(10 \mathrm{nmol})$, LTZ $(20 \mathrm{nmol})$ or allyl isothiocyanate (AITC; $10 \mathrm{nmol})$ induces paw oedema, which peaks at 60 min and fades 120 min after injection (c, upper insets), and is attenuated by pretreatment with $\mathrm{HC}\left(100 \mathrm{mg} \mathrm{kg}^{-1}\right.$ intraperitoneal, i.p.) or the combination of the selective antagonists of the neurokinin-1 receptor, (NK1-RA), L-733,060, and of the CGRP receptor (CGRP-RA), CGRP8-37, (both, $2 \mu \mathrm{mol} \mathrm{kg}{ }^{-1}$, intravenous). (d) Paw oedema induced by EXE, LTZ and AITC (i.pl.) in Trpa ${ }^{+/+}$mice is markedly reduced in Trpa ${ }^{-/-}$mice. BL $=$baseline level. Results are mean \pm s.e.m. of at least five mice for each group. Veh is the vehicle of EXE, LTZ and AITC. ${ }^{*} P<0.05$ versus Veh, Student's $t$-test; ${ }^{\$} P<0.05$ versus BL values, ${ }^{\star} P<0.05$ versus EXE, LTZ, AITC or EXE-, LTZ-, AITC-Trpa1 ${ }^{+/+}$; ANOVA followed by Bonferroni post hoc test. (e) Injection $(50 \mu \mathrm{l})$ of EXE $(5 \mathrm{nmol})$ or LTZ $(10 \mathrm{nmol})$ in the rat knee increases CGRP-LI levels in the synovial fluid, an effect that is markedly attenuated by pretreatment with $\mathrm{HC}\left(100 \mathrm{mg} \mathrm{kg}^{-1}\right.$, i.p.). Results are mean \pm s.e.m. of at least five mice for each group. Veh is the vehicle of EXE and LTZ, dash (-) indicates the vehicle of HC. ${ }^{\$} P<0.05$ versus Veh, ${ }^{\star} P<0.05$ versus EXE, LTZ; ANOVA followed by Bonferroni post hoc test. 
a

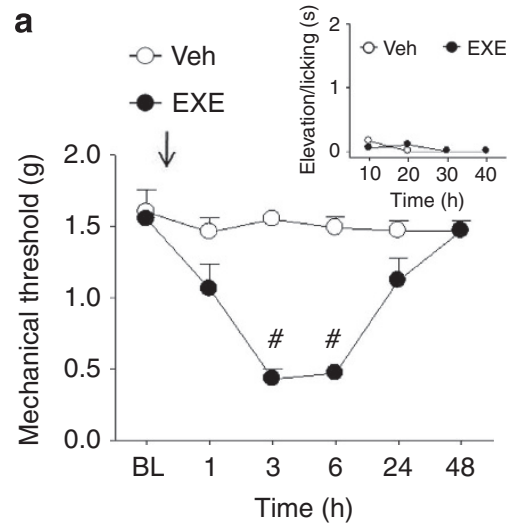

C

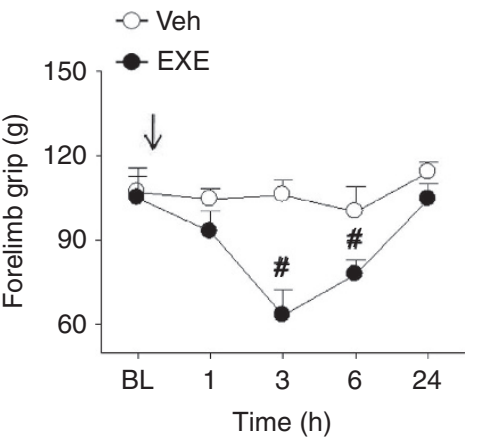

b

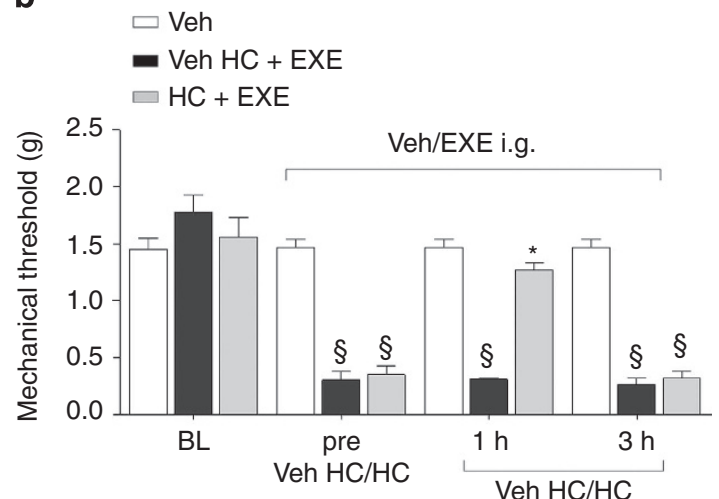

d $\square$ Veh

- Veh HC + EXE

$\square \mathrm{HC}+\mathrm{EXE}$

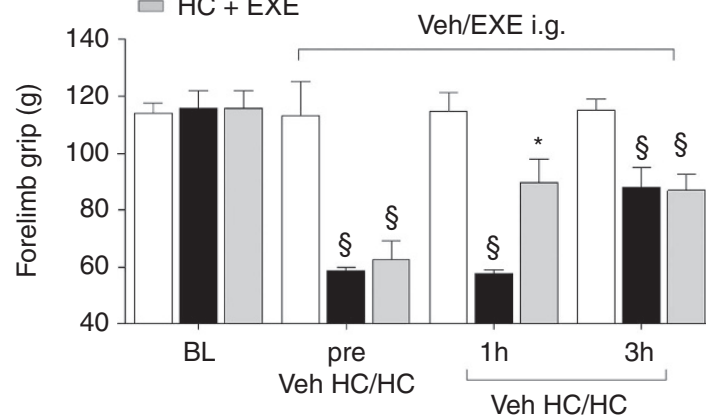

e

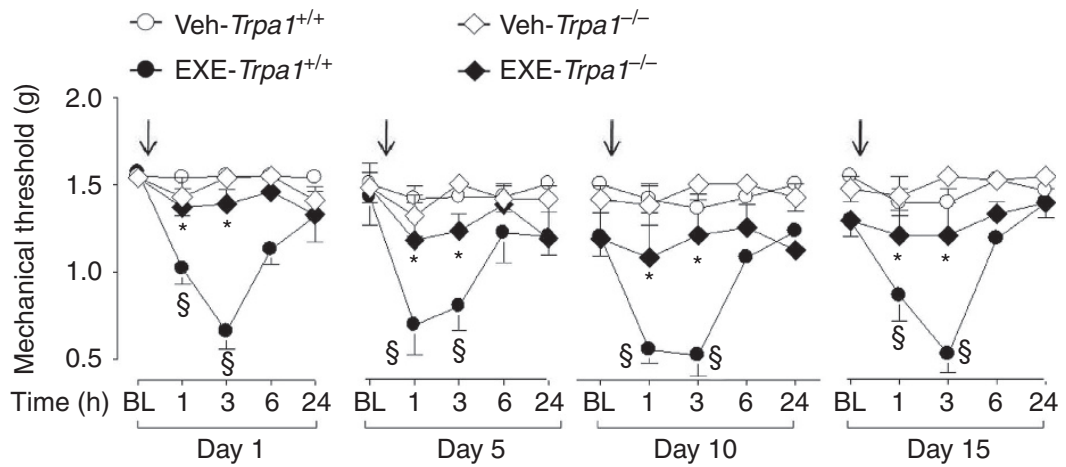

f
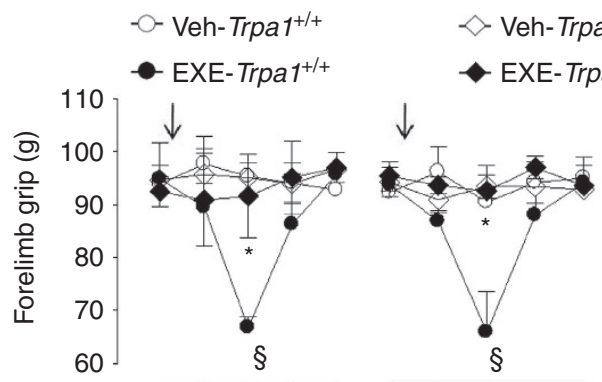

pa $1^{-1-}$

ime (h)
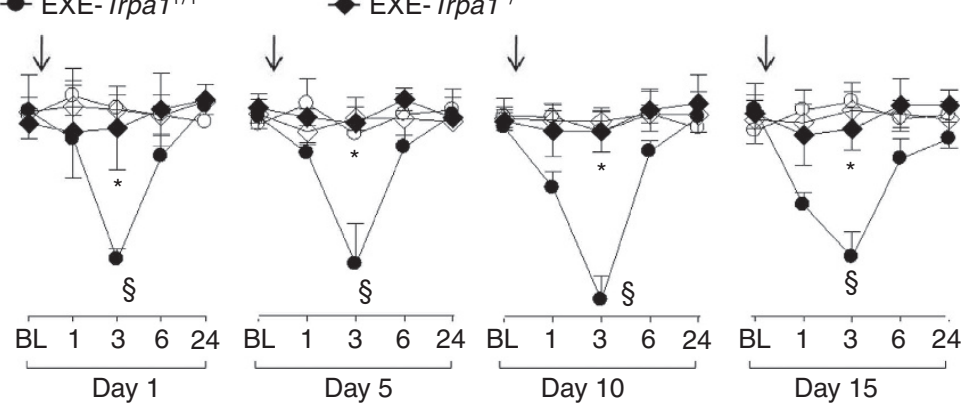

Figure 4 | Intragastric exemestane (EXE) induces TRPA1-dependent prolonged mechanical allodynia and reduction in forelimb grip strength in mice. In C57BL/6 mice intragastric (i.g.) administration of EXE $\left(10 \mathrm{mg} \mathrm{kg}^{-1}\right)$ induces (a) mechanical allodynia and (c) a reduction in forelimb grip strength that last 3-6 h after administration. EXE does not produce any acute nocifensor behaviour as measured by the indicated test (a, inset). (b,d) Three hours after EXE administration, $\mathrm{HC}-030031$ ( $\mathrm{HC} ; 100 \mathrm{mg} \mathrm{kg}^{-1}$ i.p.) reverts both mechanical allodynia and the reduction in forelimb grip strength. $\mathrm{HC}$ inhibition is no longer visible $3 \mathrm{~h}$ after its administration. Veh is the vehicle of EXE. ${ }^{\#} P<0.05$ versus Veh; Student's $t$-test $(\mathbf{a}, \mathbf{c})$ and $\$ p<0.05$ versus Veh and ${ }^{\star} P<0.05$ versus Veh HC-EXE; ANOVA followed by Bonferroni post hoc test (b,d). (e,f) EXE (once a day for 15 consecutive days, $10 \mathrm{mg} \mathrm{kg}^{-1}$ i.g.) induces reproducible mechanical allodynia and decrease in forelimb grip strength at day 1, 5, 10 and 15 in Trpa ${ }^{+/+}$mice. Arrows indicate Veh or EXE administration. Both these effects are markedly reduced in Trpa1 ${ }^{-/-}$mice. ${ }^{\$} P<0.05$ versus Veh-Trpa1 ${ }^{+/+},{ }^{\star} P<0.05$ versus EXE-Trpa1 ${ }^{+/+}$; ANOVA followed by Bonferroni post hoc test. Results are mean \pm s.e.m. of at least five mice for each group. In all conditions, baseline (BL) levels were recorded 30 min before EXE administration. 
a

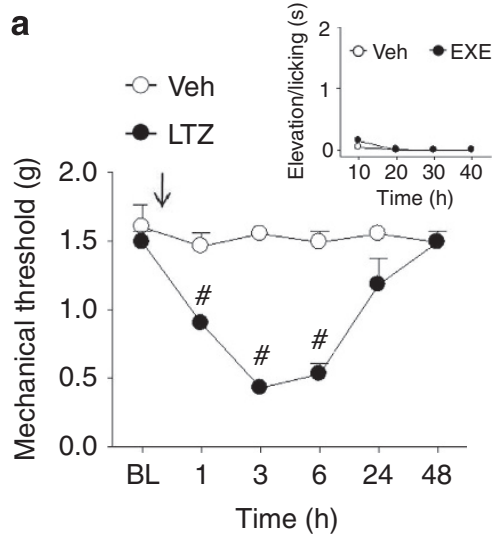

C

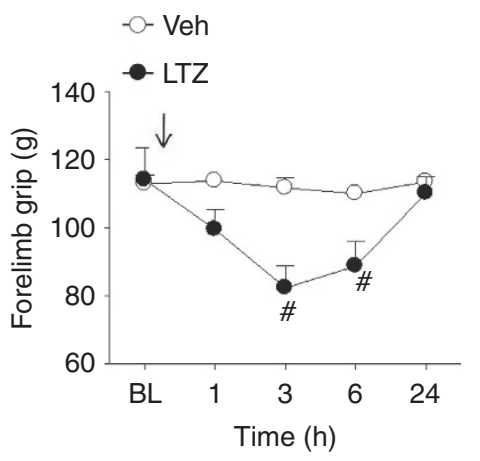

b

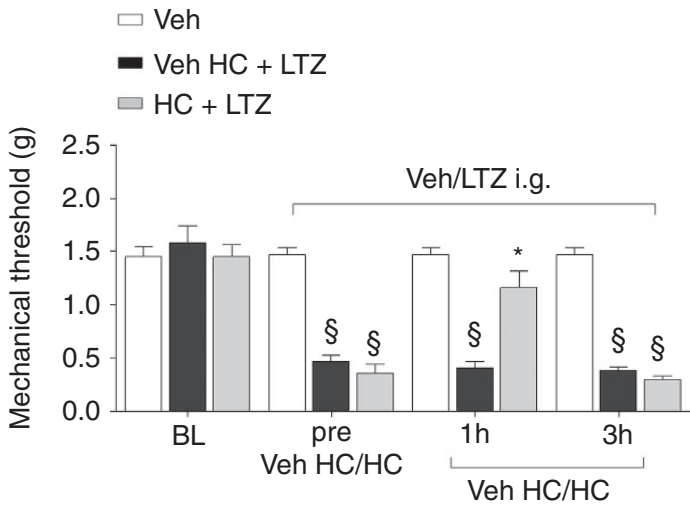

d $\square$ Veh

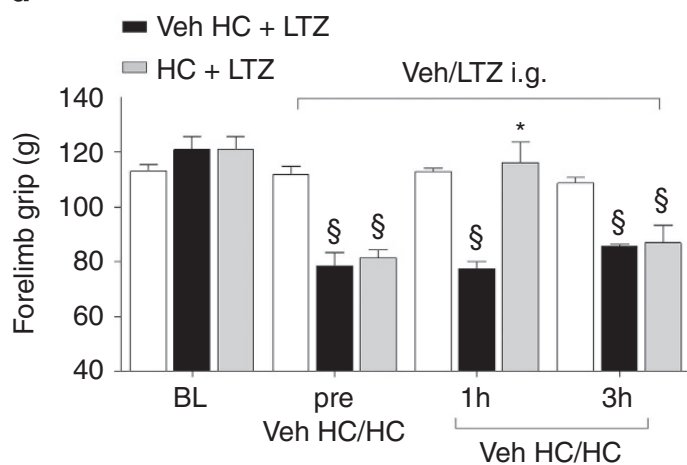

e

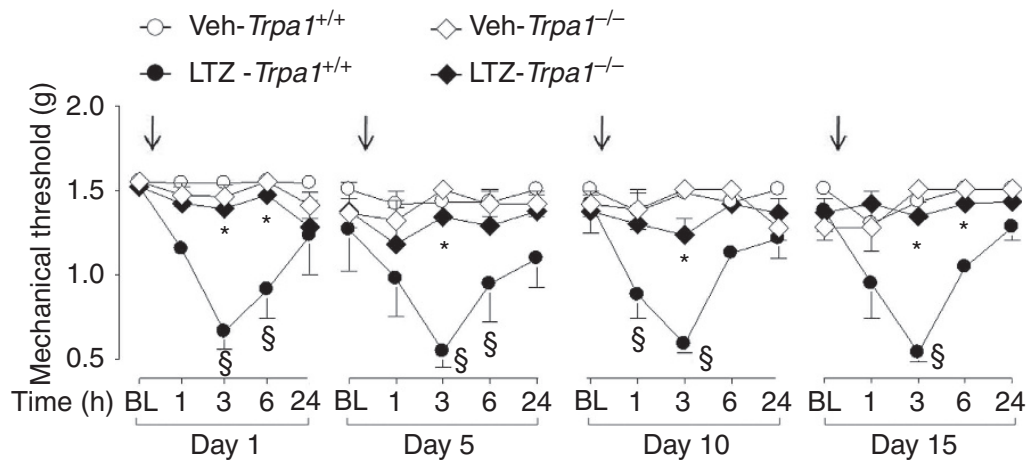

$\mathbf{f}$

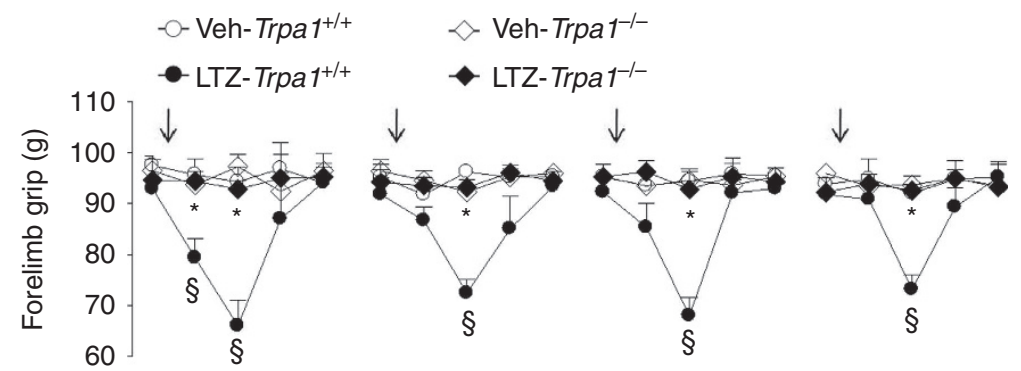

$\begin{array}{llllllllllllllllllll}\text { Time (h) BL } & 1 & 3 & 6 & 24 & \mathrm{BL} & 1 & 3 & 6 & 24 & \mathrm{BL} & 1 & 3 & 6 & 24 & \mathrm{BL} & 1 & 3 & 6 & 24\end{array}$

$$
\text { Day } 1 \text { Day } 5 \text { Day } 10 \quad \text { Day } 15
$$

Figure 5 | Intragastric letrozole (LTZ) induces TRPA1-dependent prolonged mechanical allodynia and reduction in forelimb grip strength in mice. In C57BL/6 mice intragastric (i.g.) administration of LTZ $\left(0.5 \mathrm{mg} \mathrm{kg}^{-1}\right)$ induces (a) mechanical allodynia and (c) reduction in forelimb grip strength that last 3-6 h after administration. LTZ does not produce any acute nocifensor behaviour as measured by the indicated test (a, inset). (b,d) Three hours after LTZ administration, $\mathrm{HC}-030031$ ( $\mathrm{HC} ; 100 \mathrm{mg} \mathrm{kg}^{-1}$ i.p.) reverts both mechanical allodynia and the reduction in forelimb grip strength. $\mathrm{HC}$ inhibition is no longer visible $3 \mathrm{~h}$ after its administration. Veh is the vehicle of $L T Z$. ${ }^{\#} P<0.05$ versus Veh; Student's $t$-test $(\mathbf{a}, \mathbf{c})$ and ${ }^{\$} P<0.05$ versus Veh and ${ }^{\star} P<0.05$ versus $V$ eh HC-LTZ; ANOVA followed by Bonferroni post hoc test $(\mathbf{b}, \mathbf{d})$. (e,f) LTZ (once a day for 15 consecutive days, $0.5 \mathrm{mg} \mathrm{kg}^{-1}$ i.g.) induces reproducible mechanical allodynia and decrease in forelimb grip strength at day 1, 5, 10 and 15 in Trpa ${ }^{+/+}$mice. Arrows indicate Veh or LTZ administration. Both effects are markedly reduced in Trpa1 ${ }^{-/-}$mice. ${ }^{\$} P<0.05$ versus Veh-Trpa1 ${ }^{+/+},{ }^{\star} P<0.05$ versus $\mathrm{LTZ} \mathrm{Trpa1}{ }^{+/+}$; ANOVA followed by Bonferroni post hoc test. Results are mean \pm s.e.m. of at least five mice for each group. In all conditions baseline (BL) levels were recorded 30 min before LTZ administration. 
exemestane or letrozole were inhibited by HC-030031 $\left(100 \mathrm{mg} \mathrm{kg}^{-1}\right.$, i.p.) (Fig. 6a).

We also tested the ability of a recognized endogenous TRPA1 agonist, $\mathrm{H}_{2} \mathrm{O}_{2}$ (refs 27,28) to increase the nocifensor response of exemestane or letrozole. In addition, we explored the ability of AIs to increase either nociception or mechanical allodynia to $\mathrm{H}_{2} \mathrm{O}_{2} \cdot \mathrm{H}_{2} \mathrm{O}_{2}(0.5 \mu \mathrm{mol}$ per paw $)$ injection produced a transient nocifensor behaviour that terminated within 5 min (Fig. 6b, inset). We found that $10 \mathrm{~min}$ after $\mathrm{H}_{2} \mathrm{O}_{2}$ injection (when baseline levels of nociception were restored) administration of exemestane $(1 \mathrm{nmol}$ per paw) and letrozole $(10 \mathrm{nmol}$ per paw) evoked nociceptive responses markedly increased as compared with vehicle-pretreated mice (Fig. 6b). The exaggerated responses to AIs were inhibited by HC-030031 (Fig. 6b). Thus, both homologous activation of the channel by the TRPA1 agonist $\mathrm{H}_{2} \mathrm{O}_{2}$, or heterologous stimulation of a classical proinflammatory pathway, such as PAR2, converge in a final common pathway, which results in the potentiation of the AI-evoked and TRPA1dependent proalgesic mechanism. In the attempt to understand the mechanism underlying the in vivo potentiation between PAR2 or $\mathrm{H}_{2} \mathrm{O}_{2}$ and AIs, cultured DRG neurons were challenged with combinations of these same agents. First, in in vitro electrophysiological experiments, we found that AITC, exemestane and letrozole (all $100 \mu \mathrm{M}$ ) produced inward currents in cultured DRG neurons, effects that were abated in the presence of HC-030031 $(50 \mu \mathrm{M})$. However, HC-030031 did not affect the inward current produced by capsaicin (Fig. 6c). Second, we showed that preexposure to subthreshold concentrations of PAR2-AP or $\mathrm{H}_{2} \mathrm{O}_{2}$ enhanced currents evoked by subthreshold concentrations of either exemestane or letrozole (both $20 \mu \mathrm{M}$ ) (Typical traces Fig. 6d and pooled data Fig. 6e). Third, HC-030031 inhibited the exaggerated responses (Fig. 6e).

\section{Discussion}

In the present study, we provide for the first time evidence that third-generation steroidal and non-steroidal AIs, proven to be very effective drugs in the treatment of hormone receptor-positive breast cancer ${ }^{1,2}$, selectively target the TRPA1 channel. This conclusion derives from a series of experiments in cells expressing the recombinant human TRPA1 or in rodent DRG neurons expressing the native channel. Indeed, calcium responses and currents evoked by AIs are confined to TRPA1-expressing cells, and are selectively abolished by HC-030031, or absent in neurons obtained from TRPA1-deficient mice. Exemestane exhibits a chemical structure with a system of highly electrophilic conjugated Michael acceptor groups ${ }^{40}$. A variety of known TRPA1 agonists, including acrolein and other $\alpha, \beta$ unsaturated aldehydes, possesses an electrophilic carbon or sulfur atom that is subject to nucleophilic attack (Michael addition) by cysteine and lysine residues ${ }^{55}$. Nitriles also exhibit electrophilic properties ${ }^{56}$, which may result in TRPA1 gating ${ }^{43}$. Non-steroidal letrozole and anastrozole possess nitrile moieties that underscore their potential ability to activate TRPA1. We show that key cysteine and lysine residues, required for channel activation by electrophilic agonists ${ }^{19,41,42}$, are also required for TRPA1 activation by AIs. Thus, the three AIs, most likely because of their electrophilic nature, selectively target TRPA1, whereas TRPV1, TRPV2, TRPV3 and TRPV4 all co-expressed with TRPA1 (refs 24,25), and other channels or receptors in DRG neurons do not seem to play a relevant role in the direct excitation of nociceptors by AIs.

TRPA1-expressing neurons activated by AIs also responded to capsaicin, a selective TRPV1 agonist. As TRPV1 is considered a specific marker of nociceptors ${ }^{57}$, AIs may be assumed to activate pain-like responses. In vivo stimulation of the irritant TRPA1 receptor in rodents produces an early nociceptive behaviour, followed by a delayed and prolonged mechanical allodynia ${ }^{18,19,44}$. Subcutaneous exemestane and letrozole recapitulated the two effects produced by TRPA1 agonists and produced such responses in a TRPA1-dependent way.

Magnetic resonance imaging of painful wrists in patients treated with AIs has shown signs of inflammatory tenosynovitis poorly reverted by common anti-inflammatory treatments ${ }^{12}$. Systemic increases in plasma cytokines have not been found in patients with AIMSS and, therefore, do not appear to represent the underlying mechanism for such inflammatory conditions 9 ,13 This implies that pathways different from cytokine-dependent inflammation operate in joints of patients treated with AIs. As TRPA1 is expressed by a subpopulation of peptidergic nociceptors, which mediate neurogenic inflammation ${ }^{24-26}$, we anticipated that AIs, by targeting TRPA1, release proinflammatory neuropeptides, thereby causing neurogenic plasma extravasation. Pharmacological and genetic findings indicate that AIs produce a specific type of edema, which is neurogenic in nature. The conclusion is corroborated by the direct neurochemical observation that exemestane and letrozole evoke TRPA1-dependent CGRP release from peripheral endings of primary sensory neurons. The neurogenic component, mediated by TRPA1-activation and sensory neuropeptide release, may thus represent an important mechanism contributing to the cytokineindependent inflammation observed in AI users.

When AIs were given to mice by systemic (intraperitoneal or intragastric) administration, no acute nocifensive response was observed, but, after $\sim 1 \mathrm{~h}$ delay they produced a prolonged condition (up to $6 \mathrm{~h}$ ) of mechanical allodynia and a decrease in forelimb grip strength. Also, in this case, pharmacological and genetic results indicate that AI-evoked pain-like responses are principally TRPA1-dependent. In clinical practice, AIs are used for a 3- or 5-year period, and the pain condition associated with their use is often persistent ${ }^{58}$. Although the present experimental conditions can not fully mimic the clinical setting in cancer patients, our findings suggest that the TRPA1-dependent ability of AIs to produce mechanical allodynia and to decrease forelimb grip strength is maintained and does not undergo desensitization in mice over a time period of 15 days, which broadly corresponds to a 1-year time in humans. Despite a general good tolerability ${ }^{11}$, AIs produce some types of pain, including AIMSS and neuropathic, diffuse and mixed pain in $10-20 \%$ of the treated patients ${ }^{9}$. The reason why only some of the patients exposed to AIs develop these severe pain conditions, which may lead to nonadherence or therapy discontinuation, is unknown.

Here, we reveal the key role of TRPA1 as the main mediator of exemestane- and letrozole-evoked nociceptor stimulation. However, it is likely that additional factors contribute to determine the development of AIMSS and related pain symptoms, particularly in those susceptible patients who suffer from the more severe form of this adverse reaction. In vitro and in vivo experiments with the co-administration of AIs and pro-algesic stimuli, such as PAR2-AP, an agonist of the pro-inflammatory receptor, PAR2, and the TRPA1 agonist, $\mathrm{H}_{2} \mathrm{O}_{2}$ (ref. 28), indicate that additional factors may cooperate to increase the sensitivity to AIs of TRPA1 expressing nociceptors. Enhancement by PAR2 activation of the proalgesic activity of exemestane and letrozole is fully consistent and closely mimic previous observations that PAR2 activation increases the pro-algesic response evoked by TRPA1 agonists ${ }^{52}$. Findings that a combination of AIs and $\mathrm{H}_{2} \mathrm{O}_{2}$ exaggerates TRPA1-mediated in vitro and in vivo responses suggest that increased levels of oxidative stress byproducts, known to be generated under inflammatory conditions ${ }^{59}$, may facilitate the development of AIMSS and related pain symptoms. Our present investigation on the cooperation between AIs and 
proinflammatory mediators has been limited to PAR2 and $\mathrm{H}_{2} \mathrm{O}_{2}$. However, it is possible that additional pro-inflammatory and proalgesic mediators can activate similar cooperating pathways. AI concentrations required for TRPAl activation are higher than those found in the plasma of treated subjects ${ }^{60-62}$. However, it should be noted that all three AIs have a large volume of distribution, indicating a high tissue distribution ${ }^{49,51}$. The present findings that in mice plasma levels of both AIs were comparable to those found in humans ${ }^{49,51}$ strengthen the hypothesis that compartmentalization of AIs in mice is similar to that reported in humans ${ }^{49,51}$. Thus, under standard drug regimens, concentrations sufficient to activate TRPA1 or to potentiate TRPA1mediated responses evoked in cooperation with inflammatory mediators may be reached in tissues neighbouring sensory nerve terminals.

Altogether, the present results indicate that AIs per se or, most likely, in cooperation with other proinflammatory mediators promote TRPA1-dependent neurogenic inflammation, mechanical hypersensitivity and decreased forelimb grip force in rodents. This novel pathway may represent the main underlying mechanism responsible for pain and inflammatory symptoms associated with AI treatment. The other important proposal deriving from the present findings is that antagonists of the TRPA1 channel may be beneficial in the prevention and treatment of such painful conditions.

\section{Methods \\ Animals. Animal experiments were carried out in conformity to the European Communities Council (ECC) guidelines for animal care procedures and the Italian legislation (DL 116/92) application of the ECC directive 86/609/EEC. Studies were conducted under the University of Florence research permit number 204/2012-B. Male C57BL/6 (25-30 g) (Harlan Laboratories, Milan, Italy), wild type, Trpa1 ${ }^{+1+}$, or TRPA1-deficient, Trpa1-I-,$(25-30 \mathrm{~g})$ mice generated by heterozygous on a C57BL/6 background (B6;129P-Trpaltm1 Kykw/J; Jackson Laboratories, Italy) ${ }^{63}$, or Sprague-Dawley rats (75-100 g, male, Harlan Laboratories, Milan, Italy) were used. Animals were housed in a temperature- and humidity-controlled vivarium (12 h dark/light cycle, free access to food and water). Behavioural experiments were done in a quiet, temperature-controlled $\left(20\right.$ to $\left.22^{\circ} \mathrm{C}\right)$ room between 0900 and 1700 hours and were performed by an operator blinded to the genotype and the drug treatment. Animals were killed with a high dose of sodium pentobarbital $\left(200 \mathrm{mg} \mathrm{kg}^{-1}\right.$, i.p.).}

Reagents. Exemestane, letrozole and anastrozole were purchased from Tocris Bioscience (Bristol, UK). The activating peptide (PAR2-AP, SLIGRL-NH $\mathrm{H}_{2}$ ) and its reverse peptide (PAR2-RP, LRGILS- $\mathrm{NH}_{2}$ ) of the murine PAR2 receptor were synthesized from G. Cirino (University of Naples, Naples, Italy) and dissolved in distilled water. If not otherwise indicated, all other reagents were from SigmaAldrich (Milan, Italy). HC-030031 was synthesized as previously described ${ }^{45}$.

Cell culture and isolation of primary sensory neurons. Human embryonic kidney (HEK293) cells stably transfected with the cDNA for human TRPA1 (hTRPA1-HEK293), kindly donated by A.H. Morice (University of Hull, Hull, UK) or with the cDNA for human TRPV1 (hTRPV1-HEK293), kindly donated by
Martin J. Gunthorpe (GlaxoSmithKline, Harlow, UK) and naive untransfected HEK293 cells (American Type Culture Collection, Manassas, VA, USA) were cultured as previously described ${ }^{64}$. HEK293 cells were transiently transfected with the cDNAs $(1 \mu \mathrm{g})$ codifying for wild-type or mutant 3C/K-Q (C619S, C639S, C663S, K708Q $)^{19,41}$ human TRPA1 using the jetPRIME transfection reagent (Euroclone, Milan, Italy) according to the manufacturer's protocol.

Primary DRG neurons were isolated from Sprague-Dawley rats and C57BL/6 or Trpa1 ${ }^{+1+}$ and $\operatorname{Trpa1}^{-1-}$ adult mice, and cultured as previously described ${ }^{38}$. In brief, ganglia were bilaterally excised under a dissection microscope and enzymatically digested using $2 \mathrm{mg} \mathrm{ml}^{-1}$ of collagenase type $1 \mathrm{~A}$ and $1 \mathrm{mg} \mathrm{ml}^{-1}$ of trypsin, for rat DRG neurons, or $1 \mathrm{mg} \mathrm{ml}^{-1}$ of papain, for mouse DRG neurons, in Hank's Balanced Salt Solution (HBSS) for $25-35 \mathrm{~min}$ at $37^{\circ} \mathrm{C}$. Rat and mouse DRG neurons were pelleted and resuspended in Dulbecco's Modified Eagle's Medium (DMEM) supplemented with $10 \%$ heat inactivated horse serum or Ham's-F12, respectively, containing $10 \%$ heat-inactivated fetal bovine serum (FBS),

$100 \mathrm{U} \mathrm{ml}^{-1}$ of penicillin, $0.1 \mathrm{mg} \mathrm{ml}^{-1}$ of streptomycin and $2 \mathrm{mM} \mathrm{L}$-glutamine for mechanical digestion. In this step, ganglia were disrupted by several passages through a series of syringe needles $(23-25 G)$. Neurons were then pelleted by centrifugation at $1,200 \mathrm{~g}$ for $5 \mathrm{~min}$, suspended in medium enriched with $100 \mathrm{ng} \mathrm{ml}^{-1}$ mouse-NGF and $2.5 \mathrm{mM}$ cytosine-b-D-arabino-furanoside free base, and then plated on $25 \mathrm{~mm}$ glass coverslips coated with poly-L-lysine $(8.3 \mu \mathrm{M})$ and laminin $(5 \mu \mathrm{M})$. DRG neurons were cultured for 3-4 days before being used for calcium imaging experiments.

Calcium imaging assay. Intracellular calcium was measured in transfected and untransfected HEK293 cells or in DRG neurons, as previously reported ${ }^{65}$. Plated cells were loaded with $5 \mu \mathrm{M}$ Fura-2AM-ester (Alexis Biochemicals, Lausen, Switzerland) added to the buffer solution $\left(37^{\circ} \mathrm{C}\right)$ containing the following (in $\mathrm{mM}$ ): $2 \mathrm{CaCl}_{2} ; 5.4 \mathrm{KCl} ; 0.4 \mathrm{MgSO}_{4} ; 135 \mathrm{NaCl} ; 10$ D-glucose; 10 HEPES and $0.1 \%$ bovine serum albumin at $\mathrm{pH}$ 7.4. After $40 \mathrm{~min}$, cells were washed and transferred to a chamber on the stage of a Nikon Eclipse TE-2000U microscope for recording. Cells were excited alternatively at 340 and $380 \mathrm{~nm}$ to indicate relative intracellular calcium changes by the Ratio $_{340 / 380}$ recorded with a dynamic image analysis system (Laboratory Automation 2.0, RCSoftware, Florence, Italy). Cells and neurons were exposed to exemestane, letrozole and anastrozole $(1-300 \mu \mathrm{M})$, AITC $(10-30 \mu \mathrm{M})$ menthol $(100 \mu \mathrm{M})$, icilin $(30 \mu \mathrm{M})$ or their vehicles $(1.5-3 \%$ dimethyl sulfoxide, DMSO). The calcium response to capsaicin $(0.1 \mu \mathrm{M})$ was used to identify nociceptive neurons. The selective TRPA1 antagonist, HC-030031 (30 $\mu \mathrm{M})$, and TRPV1 antagonist, capsazepine $(10 \mu \mathrm{M})$ or their vehicles $(3 \%$ and $0.1 \%$ DMSO, respectively), were applied $10 \mathrm{~min}$ before the stimuli. Results are expressed as or the percentage of increase of Ratio ${ }_{340 / 380}$ over the baseline normalized to the maximum effect induced by ionomycin $(5 \mu \mathrm{M})$ added at the end of each experiment (\% change in $\mathrm{R}_{340 / 380}$ ) or Ratio $340 / 380$.

Electrophysiology. Whole-cell patch-clamp recordings were performed on hTRPA1-HEK293, vector-HEK293 cells or rat DRG neurons grown on a poly-Llysine-coated $13 \mathrm{~mm}$-diameter glass coverslips. Each coverslip was transferred to a recording chamber ( $1 \mathrm{ml}$ volume) mounted on the platform of an inverted microscope (Olympus CKX41, Milan, Italy) and superfused at a flow rate of $2 \mathrm{ml} \mathrm{min}^{-1}$ with a standard extracellular solution containing (in $\mathrm{mM}$ ): 10 HEPES, 10 D-glucose, $147 \mathrm{NaCl}, 4 \mathrm{KCl}, 1 \mathrm{MgCl}_{2}$ and $2 \mathrm{CaCl}_{2}$ (pH adjusted to 7.4 with $\mathrm{NaOH}$ ). Borosilicate glass electrodes (Harvard Apparatus, Holliston, MA, USA) were pulled with a Sutter Instruments puller (model P-87) to a final tip resistance of 4-7 M . Pipette solution used for HEK293 cells contained (in mM): 134 K-gluconate, $10 \mathrm{KCl}, 11 \mathrm{EGTA}, 10 \mathrm{HEPES}$ ( $\mathrm{pH}$ adjusted to 7.4 with $\mathrm{KOH}$ ). When recordings were performed on rat DRG neurons, $5 \mathrm{mM} \mathrm{CaCl} 2$ was present in the extracellular solution and pipette solution contained (in $\mathrm{mM}$ ): $\mathrm{CsCl} 120$, $\mathrm{Mg}_{2}$ ATP 3, BAPTA 10, HEPES-Na 10 (pH adjusted to 7.4 with $\mathrm{CsOH}$ ). Data were acquired with an Axopatch 200B amplifier (Axon Instruments, CA, USA), stored and analysed with a pClamp 9.2 software (Axon Instruments, CA, USA). All the

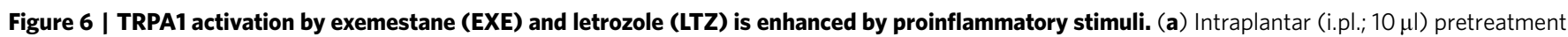
(10 min) with the proteinase-activated receptor 2 (PAR2) activating peptide (AP; $1 \mu \mathrm{g})$, but not with the inactive PAR2 reverse peptide (RP; $1 \mu \mathrm{g}$ ), enhances nocifensor behaviour produced by EXE ( $1 \mathrm{nmol}$ per $10 \mu \mathrm{l}$, i.pl.) or LTZ (10 nmol per $10 \mu l$, i.pl.). AP and RP alone causes negligible nociception. The potentiated responses to EXE or LTZ are markedly attenuated by $\mathrm{HC}-030031$ ( $\mathrm{HC} ; 100 \mathrm{mg} \mathrm{kg}{ }^{-1}$, i.p.). (b) $\mathrm{H}_{2} \mathrm{O}_{2}$ ( $0.5 \mu \mathrm{mol}$ per $10 \mu \mathrm{l}$, i.pl.) injection produces a transient nocifensor behaviour, lasting only $5 \mathrm{~min}$ (b, inset). Pretreatment (10 min before $\mathrm{Al}$ administration) with $\mathrm{H}_{2} \mathrm{O}_{2}(0.5 \mu \mathrm{mol}$ per $10 \mu \mathrm{l}$, i.pl.) increases nocifensor behaviour produced by EXE ( $1 \mathrm{nmol}$ per $10 \mu \mathrm{l}$, i.pl.) or LTZ (10 nmol per $10 \mu \mathrm{l}$, i.pl.). HC (100 mg kg ${ }^{-1}$, i.p.) inhibits the exaggerated responses to both EXE and LTZ. Dash (-) indicates the vehicle of HC. Points or columns are mean \pm s.e.m. of at least fiv mice for each group. ${ }^{\mathrm{P}}<0.05$ versus RP or

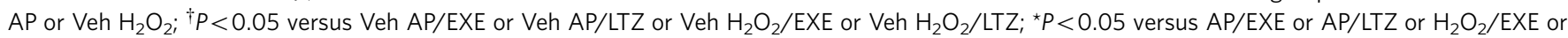
$\mathrm{H}_{2} \mathrm{O}_{2}$ /LTZ; ANOVA followed by Bonferroni post hoc test. ${ }^{\#} \mathrm{P}<0.05$ versus $V$ eh $\mathrm{H}_{2} \mathrm{O}_{2}$, Student's $t$-test. (c) An active concentration of EXE or LTZ (both $100 \mu \mathrm{M}$ ) evokes inward currents in rat dorsal root ganglion (DRG) neurons, which also respond to allyl isothiocyanate (AITC; $100 \mu \mathrm{M}$ ) and capsaicin (CPS; $1 \mu \mathrm{M})$. Inward currents evoked by EXE, LTZ or AITC are inhibited in the presence of HC (50 $\mu \mathrm{M})$, which does not affect CPS-evoked currents. Typical

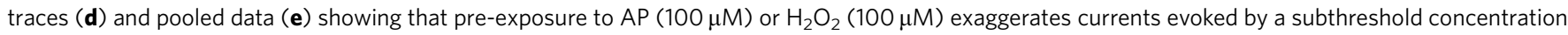
of EXE and LTZ (both $20 \mu \mathrm{M}$ ). The inactive RP does not affect responses to EXE or LTZ (both $20 \mu \mathrm{M}$ ). The potentiated responses to EXE or LTZ are markedly attenuated by $\mathrm{HC}(50 \mu \mathrm{M})$. Veh is the vehicle of EXE, LTZ and AITC. Results are mean \pm s.e.m. of at least five independent experiments. $\$ P<0.05$

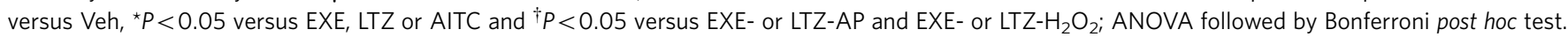


experiments were carried out at $20-22^{\circ} \mathrm{C}$. Cells were voltage-clamped at $-60 \mathrm{mV}$. Cell membrane capacitance was calculated in each cell throughout the experiment by integrating the capacitive currents elicited by a $\pm 10 \mathrm{mV}$ voltage pulse. In hTRPA1-HEK293 currents were detected as inward currents activated on cell superfusion with AITC $(100 \mu \mathrm{M})$, exemestane $(50-200 \mu \mathrm{M})$, letrozole $(50-200 \mu \mathrm{M})$ or anastrozole $(50-200 \mu \mathrm{M})$ in the presence of HC-030031 $(50 \mu \mathrm{M})$ or its vehicle
(0.5\% DMSO). TRPV1 currents in rat DRG neurons were detected as inward currents activated by capsaicin $(1 \mu \mathrm{M})$ in the presence of capsazepine $(10 \mu \mathrm{M})$ or its vehicle $\left(0.1 \%\right.$ DMSO). To evaluate the potentiating effect of $\mathrm{H}_{2} \mathrm{O}_{2}$ or PAR2-AP on AI-activated currents, rat DRG neurons were superfused with $\mathrm{H}_{2} \mathrm{O}_{2}$ or PAR2-AP (both $100 \mu \mathrm{M}$ ) $1 \mathrm{~min}$ before and during the application of exemestane or letrozole (both, $20 \mu \mathrm{M}$ ). Some experiments were performed in the presence of HC-030031

a
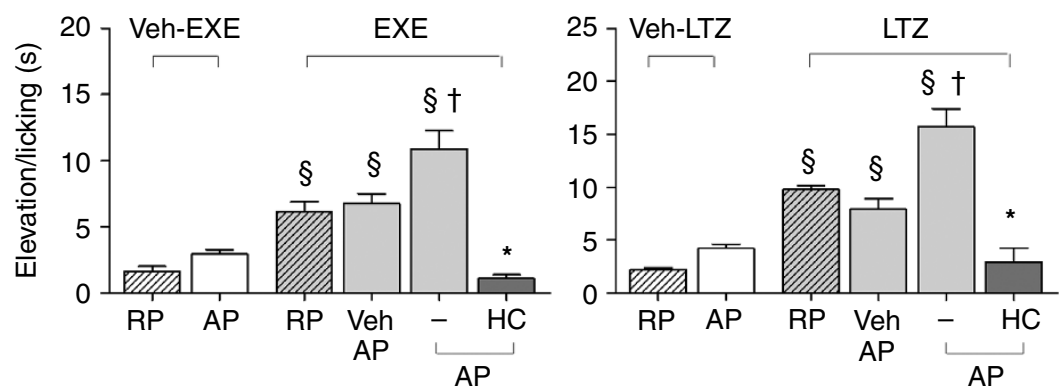

b

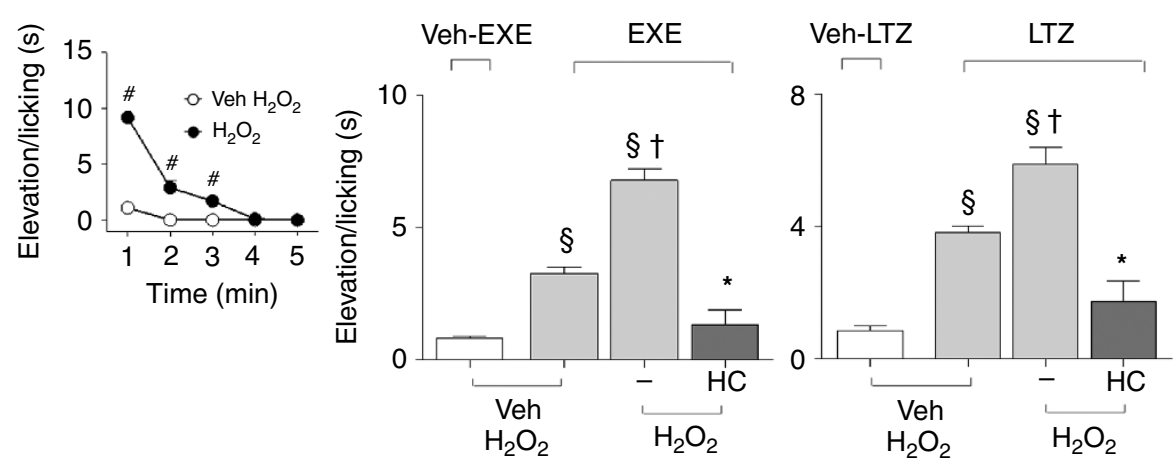

C
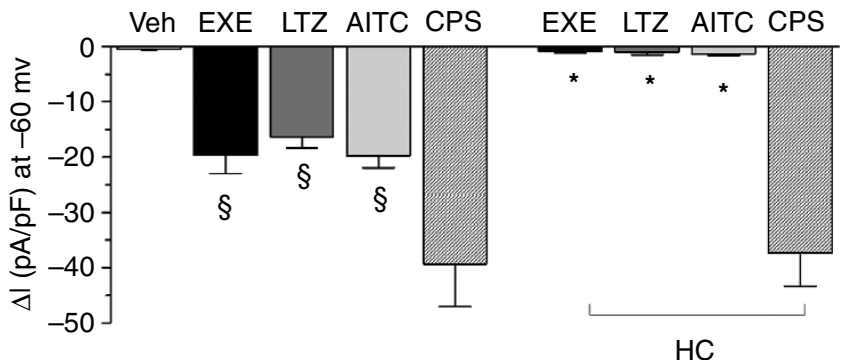

d
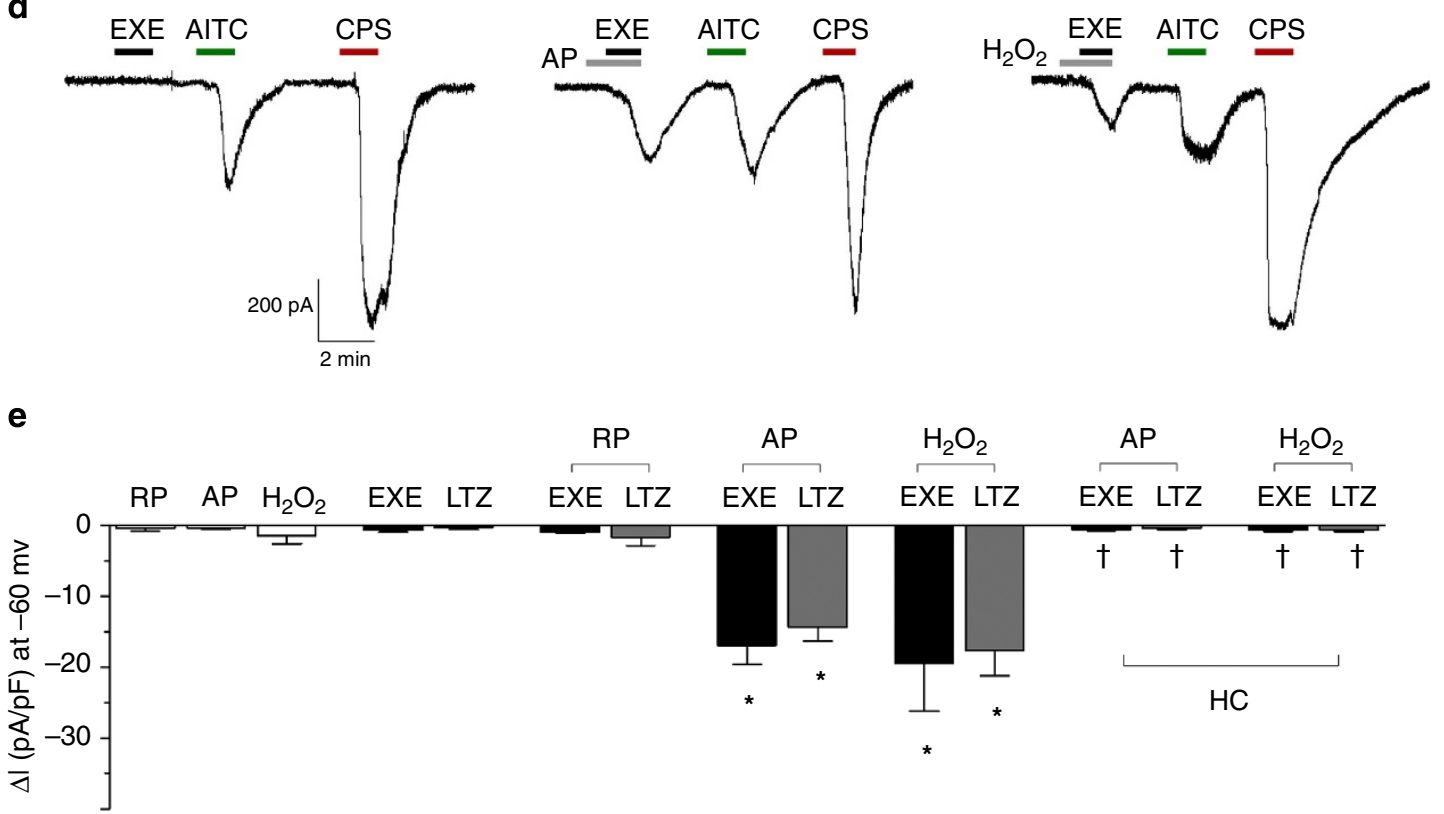
$(50 \mu \mathrm{M})$ or its vehicle (0.5\% DMSO). Peak currents activated by each compound were normalized to cell membrane capacitance and expressed as mean of the current density $(\mathrm{pA} / \mathrm{pF})$ in averaged results. Currents were evoked in the voltageclamp mode at a holding potential of $-60 \mathrm{mV}$; signals were sampled at $1 \mathrm{kHz}$ and low-pass filtered at $10 \mathrm{kHz}$.

Behavioural experiments. For behavioural experiments, after habituation and baseline of pain sensitivity measurements, mice were randomized into treatment groups. In a first series of experiments, we explored whether the injection $(20 \mu \mathrm{l}$ per paw) of exemestane $(1,5,10 \mathrm{nmol})$ or letrozole $(10,20 \mathrm{nmol})$, or their vehicle (5\% DMSO) induced, in C57BL/6 or Trpa1 ${ }^{+/+}$and $\operatorname{Trpa1}^{-/-}$mice, an acute nociceptive behaviour and a delayed mechanical allodynia. In this set of experiments mechanical allodynia was measured just before $(30 \mathrm{~min})$ and $0.25,0.5,1,2,4$ and $6 \mathrm{~h}$ post injection. Some C57BL/6 mice were pretreated with HC-030031 $\left(100 \mathrm{mg} \mathrm{kg}^{-1}\right.$, i.p.) or capsazepine $\left(10 \mathrm{mg} \mathrm{kg}^{-1}\right.$, i.p.) or their respective vehicles (4\% DMSO and $4 \%$ Tween 20 in isotonic solution), $60 \mathrm{~min}$ and $30 \mathrm{~min}$, respectively, before exemestane $(10 \mathrm{nmol})$ or letrozole $(20 \mathrm{nmol})$ i.pl. injection. Mechanical allodynia was measured $60 \mathrm{~min}$ after AIs i.pl. injection.

In a second set of experiments, nociceptive behaviour and mechanical allodynia were assayed before and after systemic administration of exemestane $\left(5 \mathrm{mg} \mathrm{kg}^{-1}\right.$, i.p. or $10 \mathrm{mg} \mathrm{kg}^{-1}$, i.g.) and letrozole $\left(0.5 \mathrm{mg} \mathrm{kg}^{-1}\right.$, i.p. or i.g.), or their vehicles $(5 \%$ DMSO for i.p. or $0.5 \%$ carboxymethylcellulose, CMC, for i.g. administration), in C57BL/6 mice or Trpa1 $1^{+1+}$ and Trpa1 ${ }^{-1-}$ mice. Mechanical allodynia was measured just before (30 $\mathrm{min}$ ) and $1,3,6,24,48 \mathrm{~h}$ after injection. Some animals $2 \mathrm{~h}$ after AI administration received HC-030031 $\left(100 \mathrm{mg} \mathrm{kg}^{-1}\right.$, i.p. $)$ or its vehicle $(4 \%$ DMSO and $4 \%$ Tween 80 in isotonic solution), and mechanical allodynia and the forelimb grip strength were measured 1 and $3 \mathrm{~h}$ after vehicle or HC-030031. In a third series of experiments, Trpa1 ${ }^{+/+}$and $\operatorname{Trpa1} 1^{-/-}$mice were treated i.p. once a day for 15 consecutive days with exemestane or letrozole at the dose of 5 or $0.5 \mathrm{mg} \mathrm{kg}^{-1}$, respectively, or with their vehicle (5\% DMSO) and with i.g. exemestane or letrozole at the dose of 10 or $0.5 \mathrm{mg} \mathrm{kg}^{-1}$, respectively, or with their vehicle $(0.5 \%$ $\mathrm{CMC}$ ). Mechanical allodynia and the forelimb grip strength were measured $10 \mathrm{~min}$ before and 1, 3,6 and $24 \mathrm{~h}$ post administration at day 1,5, 10 and 15 .

To test whether PAR2 activation enhances the nocifensor behaviour evoked by exemestane and letrozole, in another experimental setting, the PAR2 activating peptide (PAR2-AP), SLIGRL- $\mathrm{NH}_{2},(10 \mu \mathrm{g} / 10 \mu \mathrm{l}$ i.pl.) or its reversed inactive form (PAR2-RP), LRGILS- $\mathrm{NH}_{2},(10 \mu \mathrm{g}$ per $10 \mu \mathrm{l}$ i.pl.), were injected in the right hind paw. Ten minutes after i.pl. PAR2-AP or PAR2-RP injection, mice received exemestane $(10 \mathrm{nmol}$ per $10 \mu \mathrm{l}$ i.pl.) or letrozole $(20 \mathrm{nmol}$ per $10 \mu \mathrm{l}$, i.pl.), or their vehicle (5\% DMSO), in the plantar surface in the same paw injected with PAR2-AP or PAR2-RP, and the acute nociceptive behaviour was recorded. In another series of experiments $\mathrm{H}_{2} \mathrm{O}_{2}(0.5 \mu \mathrm{mol}$ per $10 \mu \mathrm{l}$, i.pl.) or its vehicle was injected and the acute nocifensor behaviour to $\mathrm{H}_{2} \mathrm{O}_{2}$, which did not last longer than $5 \mathrm{~min}$, was recorded for $10 \mathrm{~min}$. Ten minutes after vehicle $/ \mathrm{H}_{2} \mathrm{O}_{2}$, exemestane $(10 \mathrm{nmol}$ per $10 \mu \mathrm{l}$ i.pl.) or letrozole ( $20 \mathrm{nmol}$ per $10 \mu$ l, i.pl.) was injected in the same paw injected with $\mathrm{H}_{2} \mathrm{O}_{2}$ or vehicle and the acute nociceptive behaviour in response to AIs was recorded. Three hours after systemic administration of exemestane $\left(5 \mathrm{mg} \mathrm{kg}^{-1}\right.$, i.p.) or letrozole $\left(0.5 \mathrm{mg} \mathrm{kg}^{-1}\right.$, i.p.), mice were locally injected with $\mathrm{H}_{2} \mathrm{O}_{2}(0.5 \mu \mathrm{mol}$ per $20 \mu \mathrm{l}$, i.pl.) or its vehicle and both acute nocifensor behaviour and mechanical allodynia were recorded.

Acute nocifensive response. AITC ( $10 \mathrm{nmol}$ per paw), exemestane $(10 \mathrm{nmol}$ per paw), letrozole ( $20 \mathrm{nmol}$ per paw) or their vehicles (5\% DMSO), $\mathrm{H}_{2} \mathrm{O}_{2}$ $(0.5 \mu \mathrm{mol}$ per paw) or its vehicle (isotonic solution) and PAR2-AP or PAR2-RP $\left(10 \mu \mathrm{g}\right.$ per paw) $(10$ or $20 \mu \mathrm{l})$ were injected into the paw of C57BL/6, Trpa1 $1^{+/+}$ and $\operatorname{Trpa1}^{-/-}$mice, and immediately after injection animals were placed in a plexiglas chamber. The total time spent licking and lifting the injected hind paw was recorded for $5 \mathrm{~min}$ as previously described ${ }^{30}$.

Mechanical stimulation (von frey hair test). Mechanical threshold was measured in C57BL/6, Trpa1 ${ }^{+1+}$ and Trpa1 ${ }^{-1-}$ mice after both local (i.pl.) administration of AITC ( $10 \mathrm{nmol}$ per paw), exemestane ( $10 \mathrm{nmol}$ per paw), letrozole $(20 \mathrm{nmol}$ per paw) or their vehicles (5\% DMSO), $\mathrm{H}_{2} \mathrm{O}_{2}(0.5 \mu \mathrm{mol}$ per paw) or its vehicle (isotonic solution), and systemic (i.p.) administration of exemestane $\left(5 \mathrm{mg} \mathrm{kg}^{-1}\right.$, i.p.) or letrozole $\left(0.5 \mathrm{mg} \mathrm{kg}^{-1}\right.$, i.p.) at different time points by using the up-and-down paradigm ${ }^{66}$. Mechanical nociceptive threshold was determined before (basal level threshold) and after different treatments. The $50 \%$ mechanical paw withdrawal threshold response (in g) was then calculated from these scores, as previously described ${ }^{66,67}$

Forelimb grip strength test. The grip strength test was performed with a grip strength meter (Ugo Basile, Varese, Italy), as previously reported ${ }^{68}$. Mice were allowed to grasp a triangular ring attached to a force transducer and gently pulled away by the base of the tail until the grip was broken. The test was repeated four times and the mean peak force values $(\mathrm{g})$ were calculated for each animal. The grip strength was measured in C57BL/6, Trpa1 ${ }^{+/+}$and $\operatorname{Trpa1}^{-/-}$mice $10 \mathrm{~min}$ before and $1,3,6$ and $24 \mathrm{~h}$ post $\mathrm{AI}$ administration.

Paw oedema. AITC ( $10 \mathrm{nmol}$ per paw), exemestane ( $10 \mathrm{nmol}$ per paw), letrozole (20 nmol per paw) or their vehicles (5\% DMSO) (all $20 \mu \mathrm{l}$ ) were injected into the paw of C57BL/6, Trpa1 ${ }^{+/+}$and Trpa1 ${ }^{-/-}$mice, and paw thickness was measured to determine the development and severity of oedema in the hind paws. Some animals received HC-030031 (100 $\mathrm{mg} \mathrm{kg}^{-1}$, i.p.), a combination of L-733,060 and CGRP8-37 (both, $2 \mu \mathrm{mol} / \mathrm{kg}$, i.v.), or their vehicles (4\% DMSO and
$4 \%$ Tween 20 in isotonic solution for HC-030031, and isotonic solution for L-733,060 and CGRP8-37) before stimuli. An engineer's micrometer, with $0.01 \mathrm{~mm}$ accuracy (Harvard Apparatus, Kent, UK), was used to measure the paw thickness in millimeters $(\mathrm{mm})$, before and after $(60$ and $120 \mathrm{~min})$ the i.pl. injection with tested agents by an investigator blinded to treatments. Data were expressed as the increase in $\mathrm{mm}$ in paw thickness.

CGRP-like immunoreactivity (LI) assay. For neuropeptide release experiments, $0.4 \mathrm{~mm}$ slices of rat and Trpa1 ${ }^{+1+}$ or Trpa1 ${ }^{-1-}$ mouse spinal cords were superfused with an aerated $\left(95 \% \mathrm{O}_{2}\right.$ and $\left.5 \% \mathrm{CO}_{2}\right)$ Krebs solution containing (in $\mathrm{mM}$ ): $119 \mathrm{NaCl}, 25 \mathrm{NaHCO}_{3}, 1.2 \mathrm{KH}_{2} \mathrm{PO}_{4}, 1.5 \mathrm{MgSO}_{4}, 2.5 \mathrm{CaCl}_{2}, 4.7 \mathrm{KCl}, 11$ D-glucose; the solution was maintained at $37^{\circ} \mathrm{C}$, and was added with $0.1 \%$ bovine serum albumin, and, to minimize peptide degradation, with the angiotensin converting enzyme inhibitor, captopril $(1 \mu \mathrm{M})$, and the neutral endopeptidase inhibitor phosphoramidon $(1 \mu \mathrm{M})$. Tissues were stimulated with exemestane, letrozole or anastrozole (all $100 \mu \mathrm{M})$ or their vehicles $(0.05 \%$ DMSO) dissolved in the Krebs solution. Some tissues were pre-exposed to capsaicin $(10 \mu \mathrm{M}, 20 \mathrm{~min})$ or pretreated with HC-030031 $(50 \mu \mathrm{M})$. Fractions $(4 \mathrm{ml})$ of superfusate were collected at 10-min intervals before, during and after administration of the stimulus and then freezedried, reconstituted with assay buffer and analysed for CGRP-like immunoreactivity (LI) by an ELISA assay kit (Bertin Pharma, Montigny le Bretonneux, France). CGRP-LI was calculated by subtracting the mean pre-stimulus value from those obtained during or after stimulation. Detection limits of the assays were $5 \mathrm{pg} \mathrm{ml}^{-1}$ Results are expressed as femtomoles of peptide per $\mathrm{g}$ of tissue per $10 \mathrm{~min}$.

In another set of experiments, exemestane $(5 \mathrm{nmol}$ per $50 \mu \mathrm{l})$ and letrozole $(10 \mathrm{nmol}$ per $50 \mu \mathrm{l})$ or their vehicle (1\% DMSO) were i.a. injected in anaesthetized (sodium pentobarbital, $50 \mathrm{mg} \mathrm{kg}^{-1}$ i.p.) rats. Ten minutes after injection, rats were killed and the knee joint was dissected ${ }^{69}$. CGRP-LI was measured in the synovial fluid lavage added with captopril $(1 \mu \mathrm{M})$ and phosphoramidon $(1 \mu \mathrm{M})$ by using the ELISA assay kit as previously described ${ }^{69}$. Detection limits of the assays were $5 \mathrm{pg} \mathrm{ml}^{-1}$. Results are expressed as femtomoles of peptide per $\mathrm{g}$ of tissue pe $20 \mathrm{~min}$ in the spinal cord experiments or $\mathrm{pg} \mathrm{ml}^{-1}$ in the rat synovial fluid.

Assay of exemestane and letrozole by liquid chromatography-mass spectrometry. Blood samples $(100 \mu \mathrm{l})$ were obtained by venepuncture of the tail vein from each mouse at different time points $(0.25,0.5,1,3,6$ and $24 \mathrm{~h})$ after i.g. administration of exemestane $\left(10 \mathrm{mg} \mathrm{kg}^{-1}\right)$ or letrozole $\left(0.5 \mathrm{mg} \mathrm{kg}^{-1}\right)$. Blood samples were dropped on a filter paper ( 903 Whatman $\mathrm{GmbH}$, Dassel, Germany) to obtain dried blood spots $(\mathrm{DBS})^{70}$, which were punched, obtaining a $6.0 \mathrm{~mm}$ diameter disk, containing $\sim 6 \mu \mathrm{l}$ of blood. DBS transferred into a 2-ml Eppendorf vial was extracted with $200 \mu \mathrm{l}$ of methanol:water $(95: 5, \mathrm{v} / \mathrm{v})$ containing $0.1 \%$ acetic acid and the appropriate internal standard (for letrozole and exemestane quantification, extracting solutions contained $5 \mu \mathrm{gl}^{-1}$ of anastrozole or $2 \mu \mathrm{gl}^{-1}$ of letrozole, respectively) and after shaking with an orbital shaker for $25 \mathrm{~min}$ at $37^{\circ} \mathrm{C}$, solutions were dried under a gentle nitrogen stream. Residues were reconstituted with $40 \mu \mathrm{l}$ water containing $0.1 \%$ of acetic acid.

Samples were measured using a 1290 Infinity liquid chromatograph (LC, Agilent Technologies, Waldbronn, Germany) coupled to a QTRAP 5500 (AB SCIEX, Toronto, Canada) equipped with the Turbo Ion Spray source operating in positive ion mode. The capillary voltage was set to $5 \mathrm{kV}$. Heated turbo gas $\left(400^{\circ} \mathrm{C}\right.$, air) at a flow rate of $10.01 \mathrm{~min}^{-1}$ was used. The transitions (quantifier and qualifier) recorded in Multiple Reaction Monitoring (MRM) mode were 286.1>217.1 and $286.1>190.1$ for letrozole, $294.1>225.1$ and $294.1>210.1$ for anastrozole and $297.1>121.0$ and 297.1 > 93.1 for exemestane. The LC column was a Gemini C6Phenyl $\left(100 \times 2 \mathrm{~mm}^{2}, 3 \mu \mathrm{m}\right)$ with the corresponding $4 \times 2 \mathrm{~mm}^{2}$ SecurityGuardTM cartridge (Phenomenex, Torrance, CA), operated at $0.3 \mathrm{ml} \mathrm{min}^{-1}$. Eluent $\mathrm{A}$ (water $+0.1 \%$ acetic acid) and B (acetonitrile) were used. The gradient elution programme was as follows: $20 \%$ B maintained for $2 \mathrm{~min}$, then to $90 \%$ B in $7 \mathrm{~min}$, back to $20 \% \mathrm{~B}$ in $1 \mathrm{~min}$ and re-equilibrated for a $20 \mathrm{~min}$ total run time. Anastrozole, exemestane and letrozole retention times were 6.12, 6.31 and $7.45 \mathrm{~min}$, respectively. Four microlitres of the extracted sample were injected for LC-MS/MS assays. System control and data acquisition were done by Analyst 1.5.1 software, and calibration curves were calculated using the non-weighted linear least-square regression of Analyst Quantitation programme (AB SCIEX, Toronto, Canada).

Calibration curves were constructed for both exemestane and letrozole, using the appropriate internal standard. Whole-blood from control mouse was spiked with different concentrations of exemestane (from 2 to $100 \mu \mathrm{gl}^{-1}$ ) or letrozole (from 10 to $200 \mu \mathrm{gl}^{-1}$ ). A $20 \mu \mathrm{l}$ volume for each fortified blood sample was spotted on filter paper (DBS) and then treated as described in sample preparation. Each calibration curve was prepared in duplicate. Satisfying linearity was obtained for the two analytes (letrozole, $r=0.996$; exemestane, $r=0.998$ ). Each analytical batch included a double blank sample (without internal standard), a blank sample (with internal standard), five or six standard concentrations for calibration curve, and a set of treated mouse samples (each prepared in duplicate). LC-MS grade acetic acid, methanol, water and acetonitrile were supplied by Sigma Aldrich (Milan, Italy).

Statistical analysis. Data represent mean \pm s.e.m. or confidence interval (CI). Statistical analysis was performed by the unpaired two-tailed Student's $t$-test for comparisons between two groups, the ANOVA, followed by the Bonferroni post- 
hoc test for comparisons between multiple groups. Agonist potency was expressed as half maximal effective concentration $\left(\mathrm{EC}_{50}\right)$, that is, the molar concentration of agonist producing $50 \%$ of the maximum measured effect and $95 \%$ confidence interval (CI). $P<0.05$ was considered statistically significant (GraphPadPrism version 5.00, San Diego, CA).

\section{References}

1. Gibson, L., Lawrence, D., Dawson, C. \& Bliss, J. Aromatase inhibitors for treatment of advanced breast cancer in postmenopausal women. Cochrane Database Syst. Rev. 7, CD003370 (2009).

2. Burstein, H. J. et al. American Society of Clinical Oncology clinical practice guideline: update on adjuvant endocrine therapy for women with hormone receptor-positive breast cancer. J. Clin. Oncol. 28, 3784-3796 (2010).

3. Cuzick, J. et al. Effect of anastrozole and tamoxifen as adjuvant treatment for early-stage breast cancer: 10-year analysis of the ATAC trial. Lancet Oncol. 11, 1135-1141 (2013).

4. Nabholtz, J. M. Long-term safety of aromatase inhibitors in the treatment of breast cancer. Ther. Clin. Risk Manag. 4, 189-204 (2008).

5. Connor, C. \& Attai, D. Adjuvant endocrine therapy for the surgeon: options, side effects, and their management. Ann. Surg. Oncol. 20, 3188-3193 (2013)

6. Mouridsen, H. T. Incidence and management of side effects associated with aromatase inhibitors in the adjuvant treatment of breast cancer in postmenopausal women. Curr. Med. Res. Opin. 22, 1609-1621 (2006).

7. Crew, K. D. et al. Prevalence of joint symptoms in postmenopausal women taking aromatase inhibitors for early-stage breast cancer. J. Clin. Oncol. 25, 3877-3883 (2007).

8. Henry, N. L. et al. Prospective characterization of musculoskeletal symptoms in early stage breast cancer patients treated with aromatase inhibitors. Breast Cancer Res. Treat. 111, 365-372 (2008).

9. Laroche, F. et al. Classification of and risk factors for estrogen deprivation pain syndromes related to aromatase inhibitor treatments in women with breast cancer: a prospective multicenter cohort study. J. Pain 15, 293-303 (2014).

10. Burstein, H. J. \& Winer, E. P. Aromatase inhibitors and arthralgias: a new frontier in symptom management for breast cancer survivors. J. Clin. Oncol. 25, 3797-3799 (2007)

11. Presant, C. A. et al. Aromatase inhibitor-associated arthralgia and/or bone pain: frequency and characterization in non-clinical trial patients. Clin. Breast Cancer 7, 775-778 (2007)

12. Morales, L. et al. Debilitating musculoskeletal pain and stiffness with letrozole and exemestane: associated tenosynovial changes on magnetic resonance imaging. Breast Cancer Res. Treat 104, 87-91 (2007).

13. Henry, N. L. et al. Inflammatory cytokines and aromatase inhibitor-associated musculoskeletal syndrome: a case-control study. Br. J. Cancer 103, 291-296 (2010).

14. Mao, J. J. et al. Online discussion of drug side effects and discontinuation among breast cancer survivors. Pharmacoepidemiol. Drug Saf. 22, 256-262 (2013).

15. Sestak, I. et al. Risk factors for joint symptoms in patients enrolled in the ATAC trial: a retrospective, exploratory analysis. Lancet Oncol. 9, 866-872 (2008).

16. Nilius, B., Owsianik, G., Voets, T. \& Peters, J. A. Transient receptor potential cation channels in disease. Physiol. Rev. 87, 165-217 (2007).

17. Clapham, D. E. TRP channels as cellular sensors. Nature 426, 517-524 (2003).

18. Bautista, D. M. et al. TRPA1 mediates the inflammatory actions of environmental irritants and proalgesic agents. Cell 124, 1269-1282 (2006).

19. Trevisani, M. et al. 4-Hydroxynonenal, an endogenous aldehyde, causes pain and neurogenic inflammation through activation of the irritant receptor TRPA1. Proc. Natl Acad. Sci. USA 104, 13519-13524 (2007).

20. Zhang, X. F., Chen, J., Faltynek, C. R., Moreland, R. B. \& Neelands, T. R. Transient receptor potential A1 mediates an osmotically activated ion channel. Eur. J. Neurosci. 27, 605-611 (2008).

21. Bandell, M. et al. Noxious cold ion channel TRPA1 is activated by pungent compounds and bradykinin. Neuron 41, 849-857 (2004).

22. Karashima, Y. et al. TRPA1 acts as a cold sensor in vitro and in vivo. Proc. Natl Acad. Sci. USA 106, 1273-1278 (2009).

23. del Camino, D. et al. TRPA1 contributes to cold hypersensitivity. J. Neurosci. 30, 15165-15174 (2010).

24. Story, G. M. et al. ANKTM1, a TRP-like channel expressed in nociceptive neurons, is activated by cold temperatures. Cell 112, 819-829 (2003).

25. Bhattacharya, M. R. et al. Radial stretch reveals distinct populations of mechanosensitive mammalian somatosensory neurons. Proc. Natl Acad. Sci. USA 105, 20015-20020 (2008)

26. Geppetti, P. \& Holzer, P. Neurogenic Inflammation (CRC Press, 1996).

27. Andersson, D. A., Gentry, C., Moss, S. \& Bevan, S. Transient receptor potential A1 is a sensory receptor for multiple products of oxidative stress. J. Neurosci. 28, 2485-2494 (2008).
28. Sawada, Y., Hosokawa, H., Matsumura, K. \& Kobayashi, S. Activation of transient receptor potential ankyrin 1 by hydrogen peroxide. Eur. J. Neurosci. 27, 1131-1142 (2008).

29. Taylor-Clark, T. E., Ghatta, S., Bettner, W. \& Undem, B. J. Nitrooleic acid, an endogenous product of nitrative stress, activates nociceptive sensory nerves via the direct activation of TRPA1. Mol. Pharmacol. 75, 820-829 (2009).

30. Materazzi, S. et al. Cox-dependent fatty acid metabolites cause pain through activation of the irritant receptor TRPA1. Proc. Natl Acad. Sci. USA 105, 12045-12050 (2008).

31. Petrus, M. et al. A role of TRPA1 in mechanical hyperalgesia is revealed by pharmacological inhibition. Mol. Pain 3, 40 (2007).

32. Eid, S. R. et al. HC-030031, a TRPA1 selective antagonist, attenuates inflammatory- and neuropathy-induced mechanical hypersensitivity. Mol. Pain 4, 48 (2008).

33. da Costa, D. S. et al. The involvement of the transient receptor potential A1 (TRPA1) in the maintenance of mechanical and cold hyperalgesia in persistent inflammation. Pain 148, 431-437 (2010).

34. McGaraughty, S. et al. TRPA1 modulation of spontaneous and mechanically evoked firing of spinal neurons in uninjured, osteoarthritic, and inflamed rats Mol. Pain 6, 14 (2010).

35. Obata, K. et al. TRPA1 induced in sensory neurons contributes to cold hyperalgesia after inflammation and nerve injury. J. Clin. Invest. 115, 2393-2401 (2005).

36. Wei, H., Hamalainen, M. M., Saarnilehto, M., Koivisto, A. \& Pertovaara, A. Attenuation of mechanical hypersensitivity by an antagonist of the TRPA1 ion channel in diabetic animals. Anesthesiology 111, 147-154 (2009).

37. Nassini, R. et al. Oxaliplatin elicits mechanical and cold allodynia in rodents via TRPA1 receptor stimulation. Pain 152, 1621-1631 (2011).

38. Materazzi, S. et al. TRPA1 and TRPV4 mediate paclitaxel-induced peripheral neuropathy in mice via a glutathione-sensitive mechanism. Pflugers. Arch. 463, 561-569 (2012).

39. Trevisan, G. et al. Novel therapeutic strategy to prevent chemotherapy-induced persistent sensory neuropathy by TRPA1 blockade. Cancer Res. 73, 3120-3131 (2013).

40. Liu, H. \& Talalay, P. Relevance of anti-inflammatory and antioxidant activities of exemestane and synergism with sulforaphane for disease prevention. Proc. Natl Acad. Sci. USA 110, 19065-19070 (2013).

41. Hinman, A., Chuang, H. H., Bautista, D. M. \& Julius, D. TRP channel activation by reversible covalent modification. Proc. Natl Acad. Sci. USA 103, 19564-19568 (2006).

42. Macpherson, L. J. et al. An ion channel essential for sensing chemical damage. J. Neurosci. 27, 11412-11415 (2007).

43. Brone, B. et al. Tear gasses CN, CR, and CS are potent activators of the human TRPA1 receptor. Toxicol. Appl. Pharmacol. 231, 150-156 (2008).

44. McNamara, C. R. et al. TRPA1 mediates formalin-induced pain. Proc. Natl Acad. Sci. USA 104, 13525-13530 (2007).

45. Andre, E. et al. Cigarette smoke-induced neurogenic inflammation is mediated by alpha,beta-unsaturated aldehydes and the TRPA1 receptor in rodents. J. Clin. Invest. 118, 2574-2582 (2008).

46. Steinhoff, M. S., von Mentzer, B., Geppetti, P., Pothoulakis, C. \& Bunnett, N. W. Tachykinins and their receptors: contributions to physiological control and the mechanisms of disease. Physiol. Rev. 94, 265-301 (2014).

47. Reagan-Shaw, S., Nihal, M. \& Ahmad, N. Dose translation from animal to human studies revisited. Faseb J. 22, 659-661 (2008).

48. Lintermans, A. et al. Aromatase inhibitor-induced loss of grip strength is body mass index dependent: hypothesis-generating findings for its pathogenesis. Ann. Oncol. 22, 1763-1769 (2011).

49. Jin, S. J. et al. The pharmacokinetics of letrozole: association with key body mass metrics. Int. J. Clin. Pharmacol. Ther. 50, 557-565 (2012).

50. Jukanti, R., Sheela, S., Bandari, S. \& Veerareddy, P. R. Enhanced bioavailability of exemestane via proliposomes based transdermal delivery. J. Pharm. Sci. 100, 3208-3222 (2011).

51. Valle, M. et al. A predictive model for exemestane pharmacokinetics/ pharmacodynamics incorporating the effect of food and formulation. Br. J. Clin. Pharmacol. 59, 355-364 (2005).

52. Dai, Y. et al. Sensitization of TRPA1 by PAR2 contributes to the sensation of inflammatory pain. J. Clin. Invest. 117, 1979-1987 (2007).

53. Wang, S. et al. Phospholipase $\mathrm{C}$ and protein kinase A mediate bradykinin sensitization of TRPA1: a molecular mechanism of inflammatory pain. Brain 131, 1241-1251 (2008)

54. Vergnolle, N. et al. Proteinase-activated receptor-2 and hyperalgesia: A novel pain pathway. Nat. Med. 7, 821-826 (2001).

55. Dalle-Donne, I. et al. Actin Cys374 as a nucleophilic target of alpha,betaunsaturated aldehydes. Free Radic. Biol. Med. 42, 583-598 (2007).

56. Oballa, R. M. et al. A generally applicable method for assessing the electrophilicity and reactivity of diverse nitrile-containing compounds. Bioorg. Med. Chem. Lett. 17, 998-1002 (2007). 
57. Moran, M. M., McAlexander, M. A., Biro, T. \& Szallasi, A. Transient receptor potential channels as therapeutic targets. Nat. Rev. Drug Discov. 10, 601-620 (2011).

58. Kennecke, H. F. et al. Late risk of relapse and mortality among postmenopausal women with estrogen responsive early breast cancer after 5 years of tamoxifen. Ann. Oncol. 18, 45-51 (2007).

59. Sies, H. Role of metabolic $\mathrm{H} 2 \mathrm{O} 2$ generation: redox signaling and oxidative stress. J. Biol. Chem. 289, 8735-8741 (2014).

60. Spinelli, O. et al. Pharmacokinetics (PK) of Aromasin ${ }^{\circledR}$ (exemestane, EXE) after single and repeated doses in healthy postmenopausal volunteers (HPV) Eur. J. Cancer 35, S295 (1999).

61. Desta, Z. et al. Plasma letrozole concentrations in postmenopausal women with breast cancer are associated with CYP2A6 genetic variants, body mass index, and age. Clin. Pharmacol. Ther. 90, 693-700 (2011).

62. Dowsett, M., Cuzick, J., Howell, A. \& Jackson, I. Pharmacokinetics of anastrozole and tamoxifen alone, and in combination, during adjuvant endocrine therapy for early breast cancer in postmenopausal women: a subprotocol of the 'Arimidex and tamoxifen alone or in combination' (ATAC) trial. Br. J. Cancer 85, 317-324 (2001).

63. Kwan, K. Y. et al. TRPA1 contributes to cold, mechanical, and chemical nociception but is not essential for hair-cell transduction. Neuron 50, 277-289 (2006).

64. Nassini, R. et al. The 'headache tree' via umbellulone and TRPA1 activates the trigeminovascular system. Brain 135, 376-390 (2012).

65. Materazzi, S. et al. Parthenolide inhibits nociception and neurogenic vasodilatation in the trigeminovascular system by targeting the TRPA1 channel. Pain 3959, 00438-00437 (2013).

66. Chaplan, S. R., Bach, F. W., Pogrel, J. W., Chung, J. M. \& Yaksh, T. L. Quantitative assessment of tactile allodynia in the rat paw. J. Neurosci. Methods 53, 55-63 (1994).

67. Dixon, W. J. Efficient analysis of experimental observations. Annu. Rev. Pharmacol. Toxicol. 20, 441-462 (1980).

68. Doig, J. et al. In vivo characterization of the role of tissue-specific translation elongation factor $1 \mathrm{~A} 2$ in protein synthesis reveals insights into muscle atrophy. Febs J. 280, 6528-6540 (2013).

69. Trevisan, G. et al. TRPA1 receptor stimulation by hydrogen peroxide is critical to trigger hyperalgesia and inflammation in a model of acute gout. Free Radic. Biol. Med. 72, 200-209 (2014).
70. la Marca, G. et al. Rapid assay of topiramate in dried blood spots by a new liquid chromatography-tandem mass spectrometric method. J. Pharm. Biomed. Anal. 48, 1392-1396 (2008).

\section{Acknowledgements}

This work was supported by grants from Associazione Italiana per la Ricerca sul Cancro (AIRC), Milan, Italy (R.N.); Ente Cassa di Risparmio di Firenze, Florence, Italy (S.M.; G.M.); Ministero dell'Istruzione, dell'Università e della Ricerca, PRIN2010Y4WMCR-007 (S.M.) and Ministero Sviluppo Economico, IMPACT Project, Rome, Italy (P.G.)

\section{Author contributions}

C.F., R.N., S.M., P.G., S.B., M.R.D.T., T.S. and T.T. designed experiments, interpreted results and wrote the paper. C.F., S.M. and F.D.L. performed calcium experiments, E.C. performed electrophysiological experiments, R.N., I.M.M., G.T. and D.M. performed in vivo experiments, G.M. and G.P. performed mass spectrometry analyses.

\section{Additional information}

Supplementary Information accompanies this paper at http://www.nature.com/ naturecommunications

Competing financial interests: The authors declare no competing financial interests.

Reprints and permission information is available online at http://npg.nature.com/ reprintsandpermissions/

How to cite this article: Fusi, C. et al. Steroidal and non-steroidal third-generation aromatase inhibitors induce pain-like symptoms via TRPA1. Nat. Commun. 5:5736 doi: $10.1038 /$ ncomms6736 (2014).

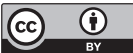

This work is licensed under a Creative Commons Attribution 4.0 International License. The images or other third party material in this article are included in the article's Creative Commons license, unless indicated otherwise in the credit line; if the material is not included under the Creative Commons license, users will need to obtain permission from the license holder to reproduce the material. To view a copy of this license, visit http://creativecommons.org/licenses/by/4.0/ 